\title{
Extracellular vesicles in patients in the acute phase of psychosis and after clinical improvement: an explorative study
}

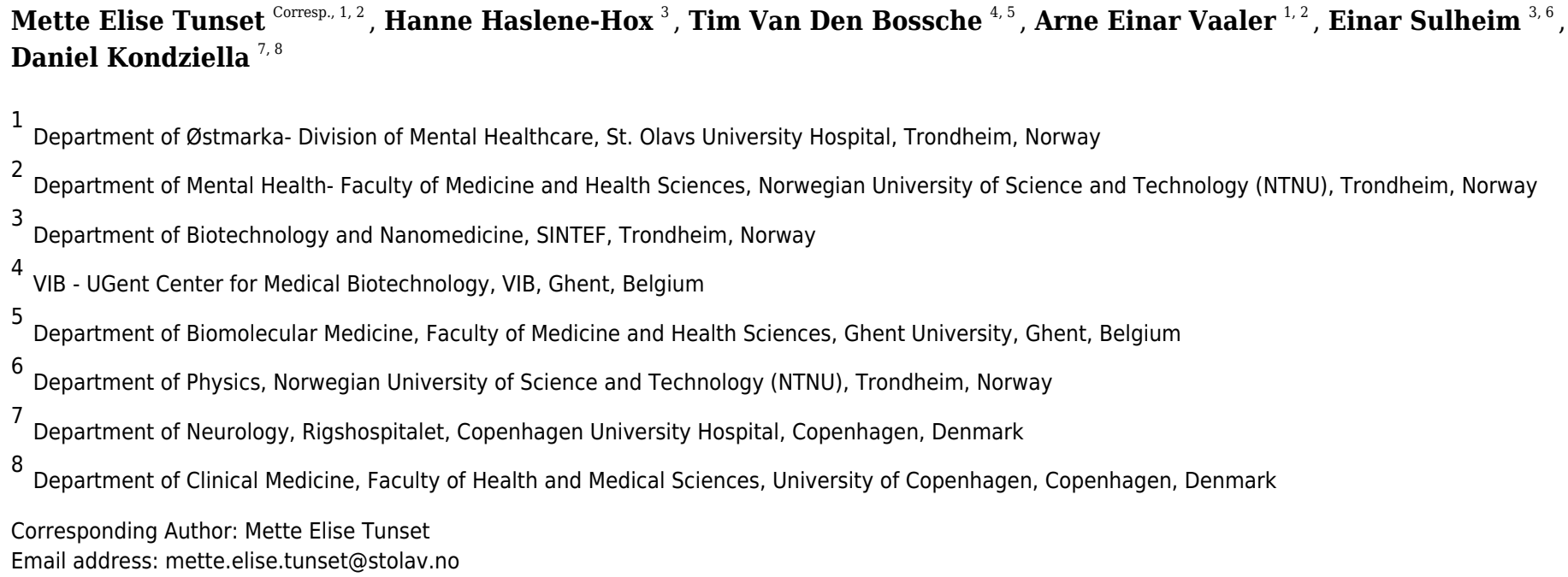

Extracellular vesicles (EVs) are cell-derived structures that transport proteins, lipids and nucleic acids between cells, thereby affecting the phenotype of the recipient cell. As the content of EVs reflects the status of the originating cell, EVs can have potential as biomarkers. Identifying EVs, including their cells of origin and their cargo, may provide insights in the pathophysiology of psychosis. Here, we present an in-depth analysis and proteomics of EVs from peripheral blood in patients $(n=25)$ during and after the acute phase of psychosis. Concentration and protein content of EVs in psychotic patients were twofold higher than in 25 age- and sex-matched healthy controls $(p<0.001$ for both concentration and protein content), and the diameter of EVs was larger in patients $(p=0.02)$. Properties of EVs did not differ significantly in blood sampled during and after the acute psychotic episode. Proteomic analyses on isolated EVs from individual patients revealed 1853 proteins, whereof 45 brain-elevated proteins were identified. Of these, five proteins involved in regulation of plasticity of glutamatergic synapses were significantly different in psychotic patients compared to controls; neurogranin (NRGN), neuron-specific calcium-binding protein hippocalcin (HPCA), kalirin (KALRN), beta-adducin (ADD2) and ankyrin-2 (ANK2). To summarize, our results show that peripheral EVs in psychotic patients are different from those in healthy controls and point at alterations in the glutamatergic system. We suggest that EVs allow investigation of blood-borne brain-originating biological material and that their role as biomarkers in patients with psychotic disorders is worthy of 
further exploration. 
1 Extracellular vesicles in patients in the acute phase of psychosis and after clinical improvement:

2 an explorative study

3

4 Mette Elise Tunset ${ }^{1,2}$; Hanne Haslene-Hox ${ }^{3}$; Tim Van Den Bossche ${ }^{4,5}$; Arne Vaaler ${ }^{1,2}$; Einar

5 Sulheim ${ }^{3,6}$; Daniel Kondziella7,8

61 -Department of $\varnothing$ stmarka, Division of Mental Healthcare, St. Olavs University Hospital

7 Trondheim, Norway

82 -Department of Mental Health- Faculty of Medicine and Health Sciences, Norwegian

9 University of Science and Technology (NTNU), Trondheim, Norway

103 - Department of Biotechnology and Nanomedicine, SINTEF, Trondheim, Norway

114 - VIB - UGent Center for Medical Biotechnology, VIB, Ghent, Belgium

125 - Department of Biomolecular Medicine, Faculty of Medicine and Health Sciences, Ghent

13 University, Ghent, Belgium

146 - Department of Physics, Norwegian University of Science and Technology (NTNU),

15 Trondheim, Norway

167 -Department of Neurology, Rigshospitalet, Copenhagen University Hospital, Copenhagen,

17 Denmark

18 8-Department of Clinical Medicine, Faculty of Health and Medical Sciences, University of

19 Copenhagen, Copenhagen, Denmark

20 Short title: 
21 Extracellular vesicles in psychosis

22 Corresponding author:

23 Mette Elise Tunset, St. Olavs University Hospital, Department of $\varnothing$ stmarka, Division of Mental

24 Healthcare, Postboks 3250 Torgarden, 7006 Trondheim, Norway

25 Email: mette.elise.tunset@stolav.no

26 ORCIDs:

27 Tunset, Mette Elise: 0000-0001-7846-7629

28 Haslene-Hox, Hanne: 0000-0001-7298-7332

29 Van Den Bossche, Tim: 0000-0002-5916-2587

30 Vaaler, Arne: 0000-0002-4630-1517

31 Sulheim, Einar: 0000-0003-3918-3345

32 Kondziella, Daniel: 0000-0001-5562-9808

33 Abstract

34 Extracellular vesicles (EVs) are cell-derived structures that transport proteins, lipids and nucleic

35 acids between cells, thereby affecting the phenotype of the recipient cell. As the content of EVs

36 reflects the status of the originating cell, EVs can have potential as biomarkers. Identifying EVs,

37 including their cells of origin and their cargo, may provide insights in the pathophysiology of psychosis. Here, we present an in-depth analysis and proteomics of EVs from peripheral blood

39 in patients $(n=25)$ during and after the acute phase of psychosis. Concentration and protein 
40

41

42

content of EVs in psychotic patients were twofold higher than in 25 age- and sex-matched healthy controls ( $p<0.001$ for both concentration and protein content), and the diameter of EVs was larger in patients ( $p=0.02)$. Properties of EVs did not differ significantly in blood sampled during and after the acute psychotic episode. Proteomic analyses on isolated EVs from individual patients revealed 1853 proteins, whereof 45 brain-elevated proteins were identified. Of these, five proteins involved in regulation of plasticity of glutamatergic synapses were significantly different in psychotic patients compared to controls; neurogranin (NRGN), neuronspecific calcium-binding protein hippocalcin (HPCA), kalirin (KALRN), beta-adducin (ADD2) and ankyrin-2 (ANK2). To summarize, our results show that peripheral EVs in psychotic patients are different from those in healthy controls and point at alterations in the glutamatergic system.

We suggest that EVs allow investigation of blood-borne brain-originating biological material and that their role as biomarkers in patients with psychotic disorders is worthy of further exploration.

\section{Introduction}

Extracellular vesicles (EVs) are nanoscale $(30-1000 \mathrm{~nm})$ cell-derived double-lipid membrane structures containing proteins, RNAs and lipids (van Niel et al. 2018; Yanez-Mo et al. 2015). They are secreted from cells by direct budding of the cell membrane (microvesicles) or by exocytosis of multivesicular bodies (exosomes). EVs are involved in signaling between cells and their cargo is not random but controlled by the originating cells (van Niel et al. 2018; Yanez-Mo et al. 2015). The proteins in EVs are common to the cells of origin, which allows to identify the tissue of origin of EVs by analyzing cell-specific proteins (van Niel et al. 2018; Yanez-Mo et al. 2015). 
61 Evidence suggests that EVs from the brain are present in peripheral blood (Galbo et al. 2017;

62 Goetzl et al. 2016a; Kapogiannis et al. 2019b). Hence, sampling of blood-borne EVs may be a

63

64

65

66

67

68

69

70

71

72

73

74

75

76

77

78

79

80

81

non-invasive way to gain access to brain-derived biological material. Since evidence indicates that EVs are involved in brain plasticity and information storage (Chivet et al. 2014; Fowler 2019; Goldie et al. 2014; Pastuzyn et al. 2018; Yanez-Mo et al. 2015), research on EVs may reveal novel insights into brain disorders in which these processes are relevant, including psychosis. Further, psychotic disorders are associated with abnormalities in several organ systems other than the brain (Pillinger et al. 2018), supporting the rational of investigating peripheral EVs in patients with psychosis. Thus, identifying EVs, their cells of origin and their cargo may uncover insights in the pathophysiology of psychosis and may serve as a source for biomarkers. In theory, EVs could also be used as therapeutic vehicles, as evidence indicates that their membrane proteins can guide them to specific recipient cells (van Niel et al. 2018; YanezMo et al. 2015). To our knowledge, there are only four published studies on psychosis and EVs: one based on brain biopsies (Banigan et al. 2013), a case report involving cerebrospinal fluid (CSF) analysis (Mobarrez et al. 2013), and two studies showing altered insulin signaling in L1 cell adhesion molecule (L1CAM) positive EVs in patients with schizophrenia (Kapogiannis et al. 2019a; Wijtenburg et al. 2019).

In the present study, we investigated if concentration, size and protein content of EVs differed between psychotic patients and controls, and if the state of the disease affected these characteristics. We also explored whether brain-derived EVs could be detected in peripheral blood, and if the pattern of brain-elevated proteins was different in patients compared to 
82 controls. Finally, we used gene ontology (GO) analysis of the proteome to explore which protein

83 categories were over-represented in significantly changed proteins.

\section{$84 \quad$ Materials and Methods}

85

86

87

88

89

90

91

92

93

94

95

Study participants

A total of 25 psychotic patients (six females, mean age $33.1 \pm 11.0$ years), during a first episode of psychosis or during acute exacerbation of a known psychotic disorder, were recruited between December 2016 to December 2018 from the $\varnothing$ stmarka acute inpatient psychiatric department, St. Olavs University Hospital, Trondheim, Norway. Exclusion criteria were affective psychoses, heart diseases, neurological diseases, pregnancy, rheumatic diseases, autoimmune diseases and cancer. In addition, patients with organic causes of psychosis were excluded. Diagnosis was assessed by ICD 10 Criteria for research and registered after discharge from hospital. Among the 25 patients, 12 (48\%) had schizophrenia, 4 (16\%) substance-induced psychotic disorder, $3(12 \%)$ acute psychosis, $3(12 \%)$ had unspecified psychosis and $3(12 \%)$ had other psychotic disorders. Mean time since onset of the first psychotic episode was 63 months \pm 81 months (if no earlier episode, time since symptom debut of the present episode was registered).

A first blood sample was taken at inclusion during the acute phase of psychosis (T1). A second blood sample was drawn 6 weeks later or more (T2), when patients were clinically back to baseline or much/very much improved according to the Clinical Global ImpressionImprovement Scale (CGI-I). The time between sample time points was $79 \pm 34$ days (range: $42-$ 162 days). The second blood sample was collected from 18 patients. Seven patients were lost to 
103 follow-up. Ongoing abuse of recreational drugs was screened for by questioning and a urine

104 drug screen at first sampling time point and by questioning at second sampling point.

105 Healthy control persons $(n=25)$ were recruited among the staff of the Department of Psychiatry, $106 \varnothing$ stmarka, St. Olavs University Hospital, Trondheim. Controls were matched to psychotic

107 patients according to sex and age (+/- 5 years). Mean age of healthy controls was $34.2 \pm 11.2$

108 years. Exclusion criteria were the same as for the psychotic patient, including (self-reported)

109 illegal substance use.

110 Scoring range

111 Clinical Global Impression-Severity Scale (CGI-S) scores were registered at both sampling points

112 by the psychologist, board-certified psychiatrist or psychiatric resident in charge of the patient.

113 The CGI-S ranges from 1 ("normal") to 7 ("among the most extremely ill") (Guy 1976).

\section{Blood sampling and EV isolation}

115 Blood $(15 \mathrm{ml})$ was collected by venipuncture in patients at the two sampling points, and in 116 control persons, with EDTA as anti-coagulant. The samples were kept on ice and centrifuged

117 fresh $\left(2000 \mathrm{~g}, 30 \mathrm{~min}, 4^{\circ} \mathrm{C}\right.$, Hettich Rotina 420R centrifuge with rotor number 4723) within 2

118 hours to isolate cell free plasma. Plasma $(6 \mathrm{ml})$ was transferred to Eppendorf tubes and

119 centrifuged $\left(10000 \mathrm{~g}, 30 \mathrm{~min}, 4^{\circ} \mathrm{C}\right.$, Eppendorf $5418 \mathrm{R}$ centrifuge with rotor number FA-45-18-

120 11). Supernatant was transferred to cryotubes, and both pellets and supernatants were frozen

121 at $-80^{\circ} \mathrm{C}$ awaiting further analysis. All samples were further processed within 1 year. 
122 Pellet fractions were thawed in room temperature and resuspended in $100 \mu$ phosphate-

123 buffered saline (PBS), and pellet samples originating from the same blood sample were pooled.

124 The samples were centrifuged again to remove any residual cells and debris, first at $2000 \mathrm{~g}$ (30

$125 \min , 4^{\circ} \mathrm{C}$, Eppendorf 5417R with rotor number FA-45-30-11). The supernatant was transferred

126 to a pre-weighed Eppendorf tube and centrifuged at $10000 \mathrm{~g}\left(30 \mathrm{~min}, 4^{\circ} \mathrm{C}\right)$. The resulting

127 supernatant was discarded, and the pellet was resuspended in ammonium bicarbonate buffer

$128(100 \mu \mathrm{l}, 100 \mathrm{mM})$ for further analysis. Samples for proteomics were frozen at $-80^{\circ} \mathrm{C}$ in Protein

129 LoBind Eppendorf tubes before further sample processing (approximately 1 month). The

130 concentration and separation approach aimed to provide an EV sample in the high recovery,

131 low specificity category of MISEV2018 guidelines(Thery et al. 2018). We have submitted all

132 relevant data of our experiments to the EV-TRACK knowledgebase (EV-TRACK ID:

133 EV200067)(Consortium et al. 2017).

134

135

136

137

138

139

140

141

142

\section{Characterization of isolated EV samples}

The protein concentration in isolated EV samples was determined by Qubit Quant-IT Protein Assay Kit (Thermo Fisher Scientific, cat. no. Q33211) on a Qubit Fluorometer 2.0. EVs were analyzed for size and concentration using Nanoparticle Tracking Analysis (NTA, Nanosight LM10, Malvern Panalytical Ltd, Malvern, UK). EVs were diluted 100-fold in sterile PBS and LM10, Malvern Panalytical Ltd, Malvern, UK). EVs were diluted 100-fold in sterile PBS and Three one-minute movies were recorded on the NTA (detection threshold 4, auto blur size, max jump distance).

Statistical analyses 
143 A two-sample un-paired $t$-test was used to compare the mean values of main characteristics of

144 EVs (size, concentration and protein content) between the patients in the acute phase of

145 psychosis and healthy controls, whereas a paired sample $t$-test was used to examine if main

146 characteristics of EV changed from the acute psychotic phase (T1) to improvement of the

147 psychotic episode (T2). To assess if a longer history of psychosis affected main characteristics of

148 EVs, we compared patients with $<1$ year since onset of first psychosis with patients with 1 year

149 or more since onset of first psychosis using two sample $t$-test (un-paired). An un-paired two-

150 sample $t$-test was also used to assess if drug abuse at the acute phase changed the

151 characteristics of EVs.

152 Proteomics of isolated EVs

153 The protein composition of EVs was determined by LC-MS/MS analysis (Choi et al. 2015).

154 Sample containing $30 \mu \mathrm{g}$ of protein as determined by Qubit was diluted to $25 \mu \mathrm{L}$ in ammonium

155 bicarbonate buffer (100 mM), digested by trypsin and desalted as described earlier (Haslene-

156 Hox et al. 2011). The sample was loaded and desalted on a pre-column for 5 minutes (Acclaim

157 PepMap 100, 2cm x 75 $\mathrm{m}$ ID nanoViper column, packed with $3 \mu \mathrm{m}$ C18 beads, flow rate:

$1585 \mu \mathrm{l} / \mathrm{min}$, mobile phase: 0.1\% TFA). For peptide separation a biphasic ACN gradient from two

159 nanoflow UPLC pumps was used (flow rate of $250 \mathrm{nl} / \mathrm{min}, 120 \mathrm{~min}$ run) on a $25 \mathrm{~cm}$ analytical

160 column (PepMap RSLC, $25 \mathrm{~cm}$ x $75 \mu \mathrm{m}$ ID EASY-spray column, packed with $2 \mu \mathrm{m}$ C18 beads with

161 pore size $100 \AA$ ). Solvent A was $0.1 \% \mathrm{FA}$ (vol/vol) in water and solvent B was $100 \%$ ACN. The

162 gradient composition was 5\%B during trapping ( $5 \mathrm{~min}$ ) 5-7\%B (0.5min), 7-22\%B (59.5min), 22-

$16335 \% \mathrm{~B}(22 \mathrm{~min})$, and $35-90 \% \mathrm{~B}(5 \mathrm{~min})$. To wash the column between samples, elution of very

164 hydrophobic peptides and conditioning of the column were performed during 10 minutes

Peer] reviewing PDF | (2020:04:47467:1:1:NEW 7 Jul 2020) 
165 isocratic elution with $80 \% \mathrm{~B}$ and 15 minutes isocratic elution with 5\%B. Peptides were ionized in 166 the electrospray and analyzed by the Q-Exactive HF. Data-dependent-acquisition (DDA) mode 167 was used to automatically switch between full scan MS and MS/MS acquisition. Q-Exactive HF 168 Tune 2.9 was used for instrument control, and XCalibur 4.1 Survey full scan MS spectra (m/z 375-1500) were acquired with resolution $R=120000$ at $\mathrm{m} / \mathrm{z} 200$, automatic gain control (AGC) target of $3 e 6$ and a maximum injection time of $100 \mathrm{~ms}$. The 12 most intense eluting peptides

171 above an intensity threshold of 50000 counts, and charge states 2 to 5, were sequentially

172 isolated to a target value (AGC) of $1 \mathrm{e} 5$ and a maximum injection time of $110 \mathrm{~ms}$ in the C-trap.

173 Isolation width was maintained at $1.6 \mathrm{~m} / \mathrm{z}$ (offset of $0.3 \mathrm{~m} / \mathrm{z}$ ), before fragmentation in the HCD

174 (Higher-Energy Collision Dissociation) cell. The minimum AGC target for fragmentation were set 175 at 5.5e3. Normalized collision energy (NCE) was $28 \%$ at fragmentation. Fragments were 176 detected at a resolution of 60000 at $\mathrm{m} / \mathrm{z} 200$, and first mass was fixed at $\mathrm{m} / \mathrm{z} 120$. One 177 precursor massMS/MS spectrum of a precursor mass was allowed before dynamic exclusion for 178 20s with "exclude isotopes" on. Lock-mass internal calibration (m/z 445.12003) was enabled. 179 Ion spray voltage was $1800 \mathrm{~V}$, no sheath and auxiliary gas flow, and capillary temperature was $180275^{\circ} \mathrm{C}$.

181 In total, 68 samples were submitted to proteomic analysis, and each sample was analysed a 182 single time with mass spectrometry in random order. The samples were divided in three 183 groups: patient samples at first time point $(n=25)$; patient samples at second time point $(n=18)$; 184 and control samples from age-matched healthy persons $(n=25)$. 
186 The raw data was converted to Mascot Generic Format (mgf) peak lists with MS convert with 187 peak picking of MS2 to convert to centroid data(Chambers et al. 2012). Peak lists obtained from $188 \mathrm{MS} / \mathrm{MS}$ spectra were identified using X!Tandem (X!Tandem Vengeance, v2015.12.15.2). The 189 search was conducted using SearchGUI (v3.3.15). Protein identification was conducted against a concatenated target/decoy database of Homo sapiens (reference proteome downloaded from UniProtKB in March 2018) (Apweiler et al. 2004) with porcine trypsin (P00761) added as possible contaminant (40660 entries in concatenated database, based on 20330 entries from uniprot.org). A reverse target sequence decoy database was created in SearchGUI (Barsnes \& Vaudel 2018). The identification was done with specific trypsin digest and maximum two missed cleavages. Tolerance was set to $10 \mathrm{ppm}$ for MS1 and 0.02 Da for MS2.

Fixed modifications was Carbamidomethylation of C (+57.021464 Da). The variable

modifications was Oxidation of $\mathrm{M}(+15.994915 \mathrm{Da})$. In addition modifications during refinement

procedure were used: Carbamidomethylation of C (+57.021464 Da, fixed), Acetylation of protein N-term (+42.010565 Da, variable), Pyrolidone from E (--18.010565 Da, variable), Pyrolidone from Q (--17.026549 Da, variable), Pyrolidone from carbamidomethylated C (-17.026549 Da, variable).

PeptideShaker (v1.16.38) (Vaudel et al. 2015) was used to infer peptides and proteins from SearchGUI spectrum identification results. Peptide Spectrum Matches (PSMs), peptides and proteins were validated at a 1.0\% False Discovery Rate (FDR) estimated using the decoy hit distribution. Post-translational modification localizations were scored using the D-score(Vaudel et al. 2013). All samples were processed in parallel in PeptideShaker to provide data for all identified proteins across all samples, with individual quantitative measures for each sample. 
208 The average precursor intensity, an average of MS1 signal for all spectra allocated to a given

209 protein in a given sample, was used for label-free quantitative evaluation.

210 Proteomic data analysis and submission of data to a repository

211 For quantification, average precursor intensities were normalized by dividing the intensity on

212 the sum of intensities within individual samples. Statistical analysis was performed using

213 Perseus (version 1.6.5.0) (Tyanova et al. 2016). Identification of significant differences in

214 protein detection between sample groups were analysed in Perseus, using Student's $t$-test with

215 correction for multiple hypothesis testing by using permutation-based FDR $<0.01$ and artificial

216 within group variance $s 0=0.1$. Missing values were imputed from a normal distribution with a

2171.8 standard deviation shift from the average and a width of 0.3.

218 Gene ontology of identified proteins was analysed by PANTHER classification system (version

219 15.0, released on 2020-04-07) (Mi et al. 2013). The EV proteome was screened for brain-

220 enriched proteins and membrane-proteins as determined in the human protein atlas (The

221 Human protein Atlas n.d.; Uhlen et al. 2015). To control for co-isolation of lipoprotein and

222 chylomicrons, we searched proteomic results for apolipoproteins (Karimi et al. 2018). The mass

223 spectrometry data along with the identification results have been deposited to the

224 ProteomeXchange Consortium (Vizcaino et al. 2014) via the PRIDE partner repository (Vizcaino

225 et al. 2016) available at http://proteomecentral.proteomexchange.org/cgi/GetDataset with the

226 dataset identifier PXD016293. EV proteome will also be deposited in the Vesiclepedia (Kalra et

227 al. 2012).

228 Ethics

Peer] reviewing PDF | (2020:04:47467:1:1:NEW 7 Jul 2020) 
229 The study was approved by the Regional Ethics committee, South East Norway (2016/949). All

230 participants gave their written, informed consent after a board-certified psychiatrist or

231 psychologist had checked that they were able to do so.

232 Results

233 Clinical Global Impression-Severity Scale

234 The CGI-S score was used to evaluate the severeness of psychosis, and the change in state for

235 patients in the two sample time points. The CGI-S score showed a decline from a median of 7

236 (defined as "among the most extremely ill patients"), range 5 to 7, during the acute psychotic

237 period (T1) to a median of 4 ("moderately ill"), range 2-6, at T2. All patients had a lower CGI-S

238 score at the second time point.

239 Size, concentration and protein content

240 Mean size and concentration of EVs and protein concentration in EV fractions are shown in

241 Figure 1. The protein concentration per EV was equal for all groups, and averaged at $1.2 \cdot 10^{-6} \pm$

$2426.7 \cdot 10^{-7} \mu \mathrm{g}$ protein/vesicles. NTA analysis showed that most vesicles in the samples was

243 between 75 and $200 \mathrm{~nm}$ in size, but larger vesicles were also present. Exosomes are defined as

244 vesicles 30-150 nm in size (Yanez-Mo et al. 2015), and the isolated samples are likely a mixture

245 of exosomes and microvesicles(the total population of vesicles is further referred to as EVs). We

246 found that the size, concentration and protein content of EVs from psychotic patients differed

247 significantly from healthy controls (Table 1A). There was no apparent difference between T1

248 and T2 in the psychotic patients (Table 1B). There were no significant differences either in EV 
249 characteristics between patients with a short (< 1 year) versus longer ( $\geq 1$ year) history of

250 psychosis (Table 1C).

251 Substance use

252 About $40 \%$ of patients with schizophrenia spectrum disorders also have a substance use

253 disorder (Hunt et al. 2018). Substance use disorders are highly correlated to smoking (Smith et

254 al. 2014) and linked with poor outcomes in symptom severity and service use in patients with

255 psychosis (Abdel-Baki et al. 2017). We studied if a recent intake of illegal substances affected EV

256 parameters. Nine and 3 patients had used illegal drugs within 1 week before T1 and T2,

257 respectively. Within the psychosis group there was no significant change in size of EVs in the

258 group without illegal substance use the week before sampling $(191 \mathrm{~nm})$ compared to patients

259 with illegal substance use 1 week before sampling $(203 \mathrm{~nm})(\mathrm{n}=25$, mean change $12 \mathrm{~nm}$,

$260 p=0.156$, equal variance not assumed) at T1. There were no differences comparing mean

261 concentrations in patients without $\left(2,46 \times 10^{7}\right.$ particles $\left./ \mathrm{ml}\right)$ and with illegal substance use 1 week

262 before sampling $\left(2,19 \times 10^{7}\right.$ particles $\left./ \mathrm{ml}\right)$ at T1 (mean change $2,75 \times 10^{6}$ particles $/ \mathrm{ml} \mathrm{n}=25$,

$263 \mathrm{p}=0.573)$. There was no significant change in mean protein content in EV fractions in patients

264 without $(28,54 \mu \mathrm{g} / \mathrm{ml})$ and with illegal substance use 1 week before sampling $(27,65 \mu \mathrm{g} / \mathrm{ml})$

$265(\mathrm{n}=25$, mean change $0,89 \mu \mathrm{g} / \mathrm{ml}, \mathrm{p}=0.897)$.

266 EV proteomes

267 The protein cargo of EVs are central to understand their origin, function and classification(Choi

268 et al. 2015). Shotgun proteomics of all EV samples resulted in 1853 identified proteins with

269 more than 1 identified peptide across all samples by 26,537 unique peptides, using a false 
positive rate (FDR) of $1 \%$ (Table S1). Of these, 1658 (89\%) proteins were identified in all three

\section{1} sample groups (Hulsen et al. 2008). 118 proteins were identified at one or two time points from

272 the psychotic patient samples, while not detected in the control group (Figure 2A). To verify the

273 EV origin, the proteomes were compared to the 100 most frequent proteins found in exosomes

274 from Exocarta (2018). We identified 93 of these in our sample material, without difference

275 between patient samples and controls. This includes known positive EV markers including

276 cytosolic proteins recovered in EVs (Alix (Q8WUM4), Tsg101 (Q99816)) and transmembrane or

277 GPI-anchored proteins associated to plasma membranes or endosomes(CD9 (P21926), CD81

278 (P60033) and CD63 (P08962)), demonstrating that the isolated EV fractions in this study

279 contained EVs(Thery et al. 2018). The enrichment of the EV proteomes was also confirmed by

280 comparing the 1853 proteins identified with the human proteome by GO enrichment analysis.

281 The GO-terms extracellular exosomes and vesicle-mediated transport were among the mostly

282 enriched GO-terms (Table S2A), verifying that the EV isolation process yielded an EV-enriched

283 fraction.

Differentially expressed proteins were identified by comparing proteins in groups pairwise by normalized average precursor intensity of identified proteins (Figure 2B). No proteins were identified as differentially expressed between T1 and T2, although COP9 signalosome complex subunit $6(Q 7 L 5 N 1)$ had significant $p$-value $(p<0.001)$ and close to significant fold change (0.66). In T1 and/or T2, 119 and 40 proteins were differentially expressed compared with healthy controls (HC), respectively (complete lists in Table S3). Combined, 131 proteins were differently expressed in T1 and/or T2 compared with HC, 102 proteins had increased 
292 relative variance and distribution for each protein between samples within one group was

293 considered to evaluate different heterogeneity in the three sample groups, and were similar for

294 HC, T1 and T2 groups. Thus, the group heterogeneity was similar for HC, T1 and T2.

295 The proteins that were differentially expressed in psychotic patients compared with healthy

296 controls were submitted to GO overrepresentation analysis, to identify enriched GO terms for

297 the changed proteins (significantly enriched GO terms compared to the human proteome, FDR

298 threshold at 0.05) (Table S2B and C).

299 Proteins with higher abundance in psychotic patients had overrepresented GO-terms related to

300 localization and transport inside and out of the cell, as well as leukocyte and neutrophil

301 activation. GO terms enriched for proteins that had a higher abundance in HC samples were

302 represented by lipoprotein processes, the immunoglobulin complex and complement pathway.

303 Of note, the GO terms main axon and postsynapse were enriched in the proteins with higher

304 abundance in healthy controls and represented 9 proteins (Table S4).

305 The mass spectrometry data along with the identification results have been deposited to the

306 ProteomeXchange Consortium (Vizcaino et al. 2014) via the PRIDE partner repository (Vizcaino

307 et al. 2016) available at http://proteomecentral.proteomexchange.org/cgi/GetDatase with the

308 dataset identifier PXD016293 and Project DOI 10.6019/PXD016293.

\section{Lipoproteins}

310 Lipoproteins are an important constituent of EVs and occur also in plasma as lipid particles that

311 can co-isolate with EVs (Raposo \& Stoorvogel 2013). Sixteen apolipoproteins were identified by

312 proteomics, including suggested markers for non-EV co-isolated structures (Apolipoprotein 
$313 \mathrm{~A} 1 / 2$ and B). Significant differences with higher levels in healthy controls were found for

314 Apolipoprotein L1, B-100, A-I and A-IV (Table S5). The apolipoproteins contributed with 1.0 to

$3156.0 \%$ of the total signal intensity for each sample analysed by proteomics (average $2.3 \%$ ),

316 indicating that the overall contribution of lipoproteins in the samples are low. The percentage

317 contribution of apolipoprotein spectra was higher in healthy controls (2.6 \pm 1.0$)$ compared with

$318 \mathrm{~T} 1(2.0 \pm 0.9)(p=0.04$, unpaired $t$-test $)$, but not T2. The GO term for chylomicron and lipid-

319 particle formation was enriched in proteins more abundant in healthy controls, also

320 corroborating that the concentration of lipid particles in $\mathrm{HC}$ compared with psychotic patients is

321 proportionally higher.

\section{Brain proteins}

323 The overall EV proteome is not dominated by brain-enhanced proteins, but include proteins

324 from EVs originating from blood cells, immune cells and endothelial cells in addition to tissue-

325 derived EVs. Proteins that can originate from the brain was identified by comparison of our EV

326 proteome with the list of genes with an elevated expression in the brain compared to other

327 tissue types in the tissue atlas of Human Protein Atlas(The Human protein Atlas n.d.; Uhlen et

328 al. 2015). These proteins have at least a four-fold higher mRNA level in the brain compared to

329 the average level in all other tissues according to The Human protein Atlas. We identified 45

330 proteins in our EV proteome (Table S6) that were also found as elevated in brain in the Human

331 Protein Atlas(The Human protein Atlas n.d.; Uhlen et al. 2015). The sum of spectral intensities

332 for all brain elevated proteins showed no difference between patients and controls. In addition

333 to the tissue categories defined by mRNA data, the Human protein atlas gives an expression

334 summary for each protein, this is based on UniProt protein existence; a Human Protein Atlas 
335

336

337

338

339

340

341

342

antibody- or RNA based score and evidence based on PeptideAtlas (The Human protein Atlas n.d.; Uhlen et al. 2015). Although this summary is not given as a score we have used it to eliminate the proteins with the lowest specificity. Five of the proteins with a high expression in the brain based on the protein expression summary had significant different abundancies in healthy controls compared to patients (Figure 3, Table 2, Student's $t$-test with correction for multiple hypothesis testing by using permutation-based FDR $<0.01$ and artificial within group variance $\mathrm{s} 0=0.1)$.$) .$

Membrane-bound protein candidates for immunolabeling of brain-derived EVs

To enable isolation of EVs from the brain, surface proteins with high specificity to the brain can be targeted either in immunoaffinity chromatography or fluorescence activated cell sorting (FACS). We have used the expression summary in the human protein atlas to identify the most brain-specific surface proteins among our identified brain elevated proteins; Plexin B3 (PLXNB3) C type lectin domain 2 family L (CLEC2L), myelin basic protein (MBP) and potassium voltagegated channel subfamily A member 2 (KCNA2) (The Human protein Atlas n.d.; Uhlen et al. 2015). We also detected purinergic receptor P2Y12(P2RY12), a surface protein with high expression in microglia (The Human protein Atlas n.d.).

\section{Discussion}

We present the first characterization of blood-based EVs isolated from psychotic patients with extensive peripheral blood EV proteomes for psychotic patients and healthy persons (BragaLagache et al. 2016), contributing to the construction of a comprehensive proteomic database for EV proteins (Choi et al. 2015). Size, concentration and protein concentration in EVs were all 
356 increased in psychotic patients compared to controls and remained unaltered with clinical

357 improvement. Use of illegal substances or duration of the psychotic disorder had no influence

358 on EV characteristics, indicating that the findings correlate to other factors than an unhealthy

359 life style which is common in patients with psychosis (Jakobsen et al. 2018). This could suggest

360 that our findings are related to the psychiatric condition itself rather than representing

361 confounders.

362 Brain-elevated proteins derived from EVs

363 We identified several brain-specific and brain-elevated proteins in isolated EVs from psychotic

364 patients and healthy controls. Brain-specific proteins have previously been found in EVs from

365 patients with malignant glioma, Alzheimer's disease (AD), frontotemporal dementia and

366 healthy controls (Galbo et al. 2017; Goetzl et al. 2016a), indicating that EVs originating from the

367 brain can enter the bloodstream. The most likely route is via the brain glymphatic system that

368 can transport large molecules and cells (Louveau et al. 2015). Transport via the blood-brain

369 barrier (BBB) may also contribute this, as preclinical evidence suggests an inflammatory dose-

370 dependent transcytosis of EVs through the BBB (Andras et al. 2017; Matsumoto et al. 2017).

371 Comparing the average content of all brain-elevated proteins, we noticed no difference

372 between patients and controls. Although a crude estimate, this suggest that the difference

373 between patients and controls in terms of total production, clearance by the glymphatics and

374 passage of brain EVs through the BBB is minor.

375 Neurogranin, neuron-specific calcium-binding protein hippocalcin, kalirin, beta-adducin and

376 ankyrin-2

PeerJ reviewing PDF | (2020:04:47467:1:1:NEW 7 Jul 2020) 
377 We found 5 brain proteins with different abundances in patients and controls; all these proteins

378 are involved in the regulation of glutamatergic synapses. GO analysis pointed in the same

379 direction as analysis of individual brain proteins; the GO terms main axon and postsynapse had

380 higher abundance in healthy controls. The formation of neuronal circuits during brain

381 development and their subsequent modification during lifetime require plasticity at excitatory

382 synapses, manifested by changes in synaptic strength (Hanley 2018). Long-term potentiation

383 (an increase in synaptic strength) and long-term depression (a decrease in synaptic strength)

384 are synapse-specific forms of plasticity (Hanley 2018). Two important postsynaptic processes

385 are involved in the plasticity of glutamatergic synapses: modifications in the amount of $\alpha$ -

386 amino-3-hydroxy-5-methyl-4-isoxazolepropionic acid receptors (AMPAR) and morphological

387 alterations of dendritic spines mainly mediated by actin filament (Bosch \& Hayashi 2012).

388 Dendritic spines are the postsynaptic structural correlate of excitatory synapses (Han et al.

389 2017).

AMPAR is a glutamate receptor that mediates the majority of fast synaptic excitation in the

central nervous system. To modulate the synaptic transmission strength, AMPAR are

transported to or from synapses (Hanley 2018). An excitatory synapse containing $N$-methyl-D-

aspartate receptors (NMDAR), but no AMPAR, is termed a silent synapse because of its low activity (Han et al. 2017). One of the main regulators of AMPAR endocytosis is stimulation of

NMDAR (Hanley 2018).

Hippocalcin, a $\mathrm{Ca}^{2+}$-sensing protein, is found in the retina and the brain and is among the proteins with the highest expression in the brain (Hanley 2018; The Human protein Atlas n.d.; Uhlen et al. 2015). Hippocalcin was increased in EVs from our psychotic patients (Figure 3B). 
399 Hippocalcin is required for long-term depression in the synapse, and a suggested mechanism is 400 that hippocalcin recruits AMPAR to endocytic sites in response to NMDAR mediated $\mathrm{Ca}^{2+}$ signals 401 (Hanley 2018).

402

403

Kalirin levels were also increased in EVs from patients (Figure 3C). Kalirin expression is enriched in the forebrain. Its most abundant isoform, kalirin-7, is localized to dendritic spines on cortical pyramidal neurons, where it plays a key role in morphological and functional plasticity at excitatory synapses and facilitates actin remodeling such that overexpression increases the number of dendritic spines (Penzes \& Remmers 2012). Kalirin-7 interacts with the protein product of, DISC1, modulating the response to NMDAR activation (Hayashi-Takagi et al. 2010; Tropea et al. 2018). When the DISC1 protein are disrupted it predisposes the carrier to a number of mental health disorders including schizophrenia (Sachs et al. 2005; Thomson et al. 2016; Tropea et al. 2018). In our study, the levels of neurogranin, beta-adducin, and ankyrin-2 were lower in EVs from psychotic patients (Figure 3A, D and E). The expression of beta-adducin is mainly restricted to the brain and hematopoietic tissues (The Human protein Atlas n.d.; Uhlen et al. 2015) and regulates dendritic spine stability through actin-based synapse formation and spectrin-based synapse stabilization (Engmann et al. 2015). Ankyrin-2 is a member of the ankyrin family of proteins that link the integral membrane proteins to the underlying spectrinactin cytoskeleton and is a key presynaptic target of casein kinase 2 to maintain synapse stability (Bulat et al. 2014). Neurogranin, a neuron-specific and postsynaptic protein, increases synaptic strength in an activity- and NMDAR-dependent manner (Zhong et al. 2009). Decreased neurogranin levels lead to accelerated spine elimination and impaired recruitment of AMPAR to silent synapses (Han et al. 2017). 
421 Our results indicate weakening of the glutamatergic synapse in psychotic patients; the high

422 levels of kalirin being an exception. The role of the detected synapse proteins as well as

423 underlying mechanisms of synaptic plasticity in general, remains little understood(Dieterich \&

424 Kreutz 2016). However, the literature does indicate an important function of EVs in synapse

425 regulation (Ashley et al. 2018; Chivet et al. 2014; Fowler 2019; Fruhbeis et al. 2013) as is also

426 apparent in our study.

427 Glutamatergic neurotransmission and psychotic disorders

428 One of the main hypotheses regarding the pathophysiology of psychotic disorders is abnormal

429 glutamatergic neurotransmission and NMDAR hypofunction (Balu \& Coyle 2015). This is

430 supported by the fact that psychosis typically starts during adolescence, a period involving

431 modification of synapses (Keshavan et al. 2014). Further, NMDAR antagonists can produce

432 psychotic symptoms (Balu \& Coyle 2015; Thiebes et al. 2017). Growing genetic data supports

433 the association between schizophrenia and glutamatergic synapse hypofunction (Fromer et al.

434 2014; Kirov et al. 2012; Schizophrenia Working Group of the Psychiatric Genomics 2014). Two

435 large genome wide studies have identified the GO term "abnormal long-term potentiation" on

436 their top list of gene sets enriched in schizophrenia (Pardinas et al. 2018; Pocklington et al.

437 2015). Two reviews also pointed at variants in genes belonging to the postsynaptic density at

438 the glutamatergic synapse (Hall et al. 2015; Soler et al. 2018). Animal models have provided

439 possible mechanisms linking NMDAR hypofunction to the perceptual disturbances and

440 abnormal associative learning in schizophrenia (Clifton et al. 2018; Ranson et al. 2019). To

441 summarize, evidence points at dysfunction of the glutamatergic synapse as a possible

442 mechanism in the pathophysiology of psychosis. Our results support data suggesting

Peer] reviewing PDF | (2020:04:47467:1:1:NEW 7 Jul 2020) 
443 glutamatergic dysfunction in psychosis and indicate a role of EVs in disease-related synaptic 444 regulation.

445 Protein candidates for immunolabeling of brain-derived EVs

446 Our proteomic analysis revealed presence of brain-derived EVs in the blood, in a mixture of EVs

447 from other tissues. The isolation of brain-derived EVs from the blood EV population can enable

448 more detailed analysis on EVs originating directly from the brain. To enable such isolation,

449 affinity methods based on antibodies recognizing surface proteins can be applied. Neural cell

450 adhesion molecule 1(NCAM1), L1CAM and glutamine aspartate transporter (SLC1A3) are

451 proteins that have been applied for immunolabeling of brain-derived EVs (Fiandaca et al. 2015;

452 Goetzl et al. 2015; Goetzl et al. 2016b; Kapogiannis et al. 2015; Kapogiannis et al. 2019b;

453 Mustapic et al. 2017). These proteins were not detected in this study indicating low

454 concentrations. L1CAM and NCAM1, have a low specificity for the brain and are thus not suited

455 for the isolation of pure fractions of brain-derived EVs(The Human protein Atlas n.d.; Uhlen et

456 al. 2015). Our study identified membrane proteins with high brain specificity(The Human

457 protein Atlas n.d.). The identified proteins are promising candidates to isolate brain-enriched

458 fractions of EVs, representing different brain cells and compartments. Although purinergic

459 receptor P2Y12 also is highly expressed in peripheral immune cells, this protein is interesting as

460 a target protein for immunolabeling of EVs due to its high expression in microglia. EVs from

461 microglia will be relevant to investigate in the future, as evidence suggests that microglia might

462 contribute to neuroinflammation in psychosis but the usefulness of PET and the translocator

463 protein tracer to assess microglia activation in patients with psychosis has been challenged

464 (Kroken et al. 2018).

Peer) reviewing PDF | (2020:04:47467:1:1:NEW 7 Jul 2020) 
466

467

468

469

470

471

472

473

474

475

476

477

GO overrepresentation analysis of significantly changed proteins revealed that immunoglobulin complex, complement pathway and lipoprotein particle-related proteins were overrepresented GO terms for proteins with significantly lower abundance in patients with psychosis. These proteins are large and abundant in human plasma(Braga-Lagache et al. 2016). The apparent increase in these GO pathways could be caused by a proportionally larger co-precipitation of free proteins and a lower overall EV concentration in healthy controls. Cholesterol and lipidsoluble proteins are also present within EVs and the detected apolipoproteins may originate from the EVs themselves (Raposo \& Stoorvogel 2013). Also, there is increasing evidence that EVs carry complement factors as cargo and on their surface, thereby contributing to both proand anti-inflammatory immune states (Karasu et al. 2018). Of note, genetic variations in some complement genes and changed levels of complement components are associated with psychosis (Woo et al. 2019).

GO terms overrepresented in proteins significantly higher in patient samples compared with healthy controls were terms related to localization and transportation within and out of the cell, as well as proteins related to activation of neutrophils and other leukocytes. This difference may indicate more active secretion and loading of EVs in psychotic patients. According to two recent meta-analyses, the neutrophil-to-lymphocyte ratio is increased in patients with non-affective psychosis and schizophrenia (Karageorgiou et al. 2019; Mazza et al. 2019), and several studies have shown other types of inflammation and immune alterations in psychotic patients (Karageorgiou et al. 2019; Kroken et al. 2018; Pillinger et al. 2018) in line with our GO analyses. Possible mechanisms could be promotion of inflammation and immune 
487 activation by EVs trough their regulatory role or inflammation stimulating EV secretion from

488 immune cells and tissues (Slomka et al. 2018).

489

490

491

492

493

494

495

496

497

498

499

500

501

502

503

504

505

506

\section{Methodological considerations}

Our study cohort consisted of acutely admitted patients with a primary diagnosis within the psychosis spectrum. This cohort reflects the real-life setting from an acute and emergency psychiatric treatment facility (Zealberg \& Brady 1999). Although a psychiatric cohort as ours is thus subject to heterogeneity, there are valid arguments against categorizing psychotic disorders into too many different diagnostic entities (Castagnini et al. 2016; Guloksuz \& van Os 2018; Pries et al. 2018). Even the validity of the distinction between a primary psychosis with comorbid drug abuse and drug-induced psychosis has been questioned (Caton et al. 2007;

Mauri et al. 2017; Wearne \& Cornish 2018; Wilson et al. 2018). From a pragmatic point of view, we therefore conclude that our cohort was suitable for the aim of our study, i.e. investigating EVs in patients in the acute phase of psychosis and after improvement.

Selection of anti-coagulant, concentration steps and freezing and thawing EV samples are all steps that may affect the size or concentration of vesicles in the samples (Barrachina et al. 2019). We aimed to start the EV isolation with fresh samples. However, complete EV isolation and further processing of fresh samples were not feasible in a clinical setting. All samples were centrifuged to remove cells $(2000 \mathrm{~g}$ ) and subsequently pellet large EVs (at $10,000 \mathrm{~g}$ ) before EV pellets were frozen prior to further analysis, to ensure that all samples were treated equally. An additional centrifugation step to wash the EV samples after freezing were done to remove the 
507 largest aggregates that may have formed due to anti-coagulant activity or freezing and thawing,

508 likely causing a loss of vesicles, as some vesicles have aggregated and were removed.

509 The use of EDTA as anti-coagulant has been shown to stimulate platelet-derived vesicle

510 formation in some studies (Mullier et al. 2013). Thus, we cannot rule out that the use of EDTA

511 or the analysis of frozen EV samples could affect the EV size and concentration as measured

512 with NTA (Figure 1). Nevertheless, studies have also shown that both anti-coagulant and

513 freezing had limited effect on EVs isolated from platelet poor plasma (Jamaly et al. 2018).

514 Furthermore, we are comparing groups of samples that have been treated identically, to ensure

515 that results are comparable between sample groups.

516 Regarding the isolation of EVs, our method is simple, and aims to provide a sample of sufficient

517 EVs for further analysis, with high recovery and low specificity that will contain both small and

518 large EVs, but excluding the smallest EVs, because ultracentrifugation was not applied (Thery et

519 al. 2018). As the yield of EVs from a normal-sized peripheral blood sample is modest, our

520 available sample volumes were not sufficient for dividing the samples into more defined,

521 smaller, fractions, e.g. by a density gradient separation method. However, by comparison with

522 Exocarta and gene ontology, we demonstrated that the obtained samples are highly enriched in

523 EVs, and a number of positive EV markers were identified by proteomics. We also identified

524 apolipoproteins and albumin, which are common non-EV contaminant proteins from blood

525 (Thery et al. 2018), indicating the co-isolation also of soluble proteins or protein aggregates not

526 originating from inside the EVs. Preliminary experiments were also done on selected samples,

527 to isolate smaller vesicles from the supernatant by ultracentrifugation at $110,000 \mathrm{~g}$, to evaluate

528 if this could provide us with additional fractions of smaller EVs in sufficient volumes. However, 
529 proteomic analysis of such samples revealed predominately abundant plasma proteins, and

530 none of the expected EV protein markers that were identified in the $10,000 \mathrm{~g}$ fraction (data not

531 shown). We conclude that the isolation method used in this study yields samples enriched with

532 important EVprotein markers and with sufficient EV amounts for in-depth characterization of

533 individual samples.

534 Strengths and limitations

535 Our study has limitations that should be acknowledged. First, this was an explorative study with

536 a small and heterogenous patient cohort. Second, we were unable to control for weight,

537 smoking and metabolic factors that are expected to be unequally distributed in psychotic

538 patients and controls. Third, our study may have been subject to selection bias with the most

539 paranoid and anxious patients declining consent; and finally, $28 \%$ of patients with psychosis

540 was lost to follow-up. On the positive side, this is the first study that characterizes peripheral

541 EVs in psychosis, i.e. a novel and promising opportunity to identify biomarkers for a major

542 psychiatric disorder.

\section{Conclusions}

544 Blood-borne EVs differ substantially between patients with psychotic disorders and healthy

545 controls. Also, amounts of several proteins involved in the regulation of plasticity of

546 glutamatergic synapses were altered in the psychotic patients supporting evidence of

547 glutamatergic dysfunction in psychosis and indicate a role of EVs in disease-related synaptic

548 regulation. These should be validated and studied in more detail, to progress the understanding

549 of the role of these proteins in psychosis. Thus, collecting peripheral EVs allows access to brain- 
550 originating biological material and may provide novel insights about the underlying processes of

551 psychotic disorders. This study also contribute towards the construction of a comprehensive

552 proteome database for EVs, reporting the first proteomic data for EVs in psychosis, and

553 providing data necessary to further elucidate the biogenesis, cargo and pathophysiological role

554 of EVs. We suggest that future studies investigate more thoroughly if potential confounders as

555 lifestyle factors, medications or high stress levels contribute to the changed EV profile in

556 patients with psychotic disorders. The suitability of identified surface brain proteins as tools to

557 isolate a "liquid brain biopsy" should also be evaluated further. Eventually, if our findings in the

558 glutamatergic proteins are confirmed it will be highly relevant to study their mechanistic role as

559 related to EVs.

560 Acknowledgment

561 We thank Olav Mjaavatten and Even Birkeland at the Proteomics Unit of the University of

562 Bergen (PROBE) for performing mass spectrometry analysis and Harald Barsnes from the

563 University of Bergen for assistance with proteomic software. We also thank the laboratory and

564 Kjetil Sørensen at $\varnothing$ stmarka, St Olavs University Hospital and the Clinic of Laboratory Medicine

565 at St Olavs University Hospital for practical support with blood sampling and initial preparation

566 of samples.

\section{References}

568 2018. Exocarta. Available at http://exocarta.org/exosome_markers_new (accessed October.

569 Abdel-Baki A, Ouellet-Plamondon C, Salvat E, Grar K, and Potvin S. 2017. Symptomatic and functional

$570 \quad$ outcomes of substance use disorder persistence 2 years after admission to a first-episode

$571 \quad$ psychosis program. Psychiatry Research 247:113-119. 10.1016/j.psychres.2016.11.007 
572

573

574

575

576

577

578

579

580

581

582

583

584

585

586

587

588

589

590

591

592

593

594

595

596

597

598

599

600

601

602

603

604

605

606

607

608

609

610

611

612

613

614

615

616

617

618

619

Andras IE, Leda A, Contreras MG, Bertrand L, Park M, Skowronska M, and Toborek M. 2017. Extracellular vesicles of the blood-brain barrier: Role in the HIV-1 associated amyloid beta pathology. Molecular and Cellular Neurosciences 79:12-22. 10.1016/j.mcn.2016.12.006

Apweiler R, Bairoch A, Wu CH, Barker WC, Boeckmann B, Ferro S, Gasteiger E, Huang H, Lopez R, Magrane M, Martin MJ, Natale DA, O'Donovan C, Redaschi N, and Yeh LS. 2004. UniProt: the universal protein knowledgebase. Nucleic Acids Research 32:D115-119. 10.1093/nar/gkh131

Ashley J, Cordy B, Lucia D, Fradkin LG, Budnik V, and Thomson T. 2018. Retrovirus-like Gag protein Arc1 binds RNA and traffics across synaptic boutons. Cell 172:262-274 e211. 10.1016/j.cell.2017.12.022

Balu DT, and Coyle JT. 2015. The NMDA receptor 'glycine modulatory site' in schizophrenia: D-serine, glycine, and beyond. Current Opinion in Pharmacology 20:109-115. 10.1016/j.coph.2014.12.004

Banigan MG, Kao PF, Kozubek JA, Winslow AR, Medina J, Costa J, Schmitt A, Schneider A, Cabral H, Cagsal-Getkin O, Vanderburg CR, and Delalle I. 2013. Differential expression of exosomal microRNAs in prefrontal cortices of schizophrenia and bipolar disorder patients. PloS One 8:e48814. 10.1371/journal.pone.0048814

Barrachina MN, Calderon-Cruz B, Fernandez-Rocca L, and Garcia A. 2019. Application of extracellular vesicles proteomics to cardiovascular disease: Guidelines, data analysis, and future perspectives. Proteomics 19:e1800247. 10.1002/pmic.201800247

Barsnes H, and Vaudel M. 2018. SearchGUI: A highly adaptable common interface for proteomics search and de novo engines. Journal of Proteome Research 17:2552-2555. 10.1021/acs.jproteome.8b00175

Bosch M, and Hayashi Y. 2012. Structural plasticity of dendritic spines. Current Opinion in Neurobiology 22:383-388. 10.1016/j.conb.2011.09.002

Braga-Lagache S, Buchs N, lacovache MI, Zuber B, Jackson CB, and Heller M. 2016. Robust label-free, quantitative profiling of circulating plasma microparticle (MP) associated proteins. Molecular \& Cellular Proteomics 15:3640-3652. 10.1074/mcp.M116.060491

Bulat V, Rast M, and Pielage J. 2014. Presynaptic CK2 promotes synapse organization and stability by targeting Ankyrin2. Journal of Cell Biology 204:77-94. 10.1083/jcb.201305134

Castagnini AC, Munk-Jorgensen P, and Bertelsen A. 2016. Short-term course and outcome of acute and transient psychotic disorders: Differences from other types of psychosis with acute onset. International Journal of Social Psychiatry 62:51-56. 10.1177/0020764015590493

Caton CL, Hasin DS, Shrout PE, Drake RE, Dominguez B, First MB, Samet S, and Schanzer B. 2007. Stability of early-phase primary psychotic disorders with concurrent substance use and substanceinduced psychosis. British Journal of Psychiatry 190:105-111. 10.1192/bjp.bp.105.015784

Chambers MC, Maclean B, Burke R, Amodei D, Ruderman DL, Neumann S, Gatto L, Fischer B, Pratt B, Egertson J, Hoff K, Kessner D, Tasman N, Shulman N, Frewen B, Baker TA, Brusniak MY, Paulse C, Creasy D, Flashner L, Kani K, Moulding C, Seymour SL, Nuwaysir LM, Lefebvre B, Kuhlmann F, Roark J, Rainer P, Detlev S, Hemenway T, Huhmer A, Langridge J, Connolly B, Chadick T, Holly K, Eckels J, Deutsch EW, Moritz RL, Katz JE, Agus DB, MacCoss M, Tabb DL, and Mallick P. 2012. A cross-platform toolkit for mass spectrometry and proteomics. Nature Biotechnology 30:918-920. $10.1038 / \mathrm{nbt} .2377$

Chivet M, Javalet C, Laulagnier K, Blot B, Hemming FJ, and Sadoul R. 2014. Exosomes secreted by cortical neurons upon glutamatergic synapse activation specifically interact with neurons. J Extracell Vesicles 3:24722. 10.3402/jev.v3.24722

Choi DS, Kim DK, Kim YK, and Gho YS. 2015. Proteomics of extracellular vesicles: Exosomes and ectosomes. Mass Spectrometry Reviews 34:474-490. 10.1002/mas.21420

Clifton NE, Thomas KL, and Hall J. 2018. The effect of ketamine on the consolidation and extinction of contextual fear memory. J Psychopharmacol 32:156-162. 10.1177/0269881117748903

PeerJ reviewing PDF | (2020:04:47467:1:1:NEW 7 Jul 2020) 
620

621

622

623

624

625

626

627

628

629

630

631

632

633

634

635

636

637

638

639

640

641

642

643

644

645

646

647

648

649

650

651

652

653

654

655

656

657

658

659

660

661

662

663

664

665

666

Consortium E-T, Van Deun J, Mestdagh P, Agostinis P, Akay O, Anand S, Anckaert J, Martinez ZA, Baetens $T$, Beghein E, Bertier L, Berx G, Boere J, Boukouris S, Bremer M, Buschmann D, Byrd JB, Casert C, Cheng L, Cmoch A, Daveloose D, De Smedt E, Demirsoy S, Depoorter V, Dhondt B, Driedonks TA, Dudek A, Elsharawy A, Floris I, Foers AD, Gartner K, Garg AD, Geeurickx E, Gettemans J, Ghazavi F, Giebel B, Kormelink TG, Hancock G, Helsmoortel H, Hill AF, Hyenne V, Kalra H, Kim D, Kowal J, Kraemer S, Leidinger $P$, Leonelli C, Liang Y, Lippens L, Liu S, Lo Cicero A, Martin S, Mathivanan S, Mathiyalagan P, Matusek T, Milani G, Monguio-Tortajada M, Mus LM, Muth DC, Nemeth A, Nolte-'t Hoen EN, O'Driscoll L, Palmulli R, Pfaffl MW, Primdal-Bengtson B, Romano E, Rousseau Q, Sahoo S, Sampaio N, Samuel M, Scicluna B, Soen B, Steels A, Swinnen JV, Takatalo M, Thaminy S, Thery C, Tulkens J, Van Audenhove I, van der Grein S, Van Goethem A, van Herwijnen MJ, Van Niel G, Van Roy N, Van Vliet AR, Vandamme N, Vanhauwaert S, Vergauwen G, Verweij F, Wallaert A, Wauben M, Witwer KW, Zonneveld MI, De Wever O, Vandesompele J, and Hendrix A. 2017. EV-TRACK: transparent reporting and centralizing knowledge in extracellular vesicle research. Nat Methods 14:228-232. 10.1038/nmeth.4185

Dieterich DC, and Kreutz MR. 2016. Proteomics of the synapse--a quantitative approach to neuronal plasticity. Molecular \& Cellular Proteomics 15:368-381. 10.1074/mcp.R115.051482

Engmann O, Giralt A, Gervasi N, Marion-Poll L, Gasmi L, Filhol O, Picciotto MR, Gilligan D, Greengard P, Nairn AC, Herve D, and Girault JA. 2015. DARPP-32 interaction with adducin may mediate rapid environmental effects on striatal neurons. Nat Commun 6:10099. 10.1038/ncomms10099

Fiandaca MS, Kapogiannis D, Mapstone M, Boxer A, Eitan E, Schwartz JB, Abner EL, Petersen RC, Federoff HJ, Miller BL, and Goetzl EJ. 2015. Identification of preclinical Alzheimer's disease by a profile of pathogenic proteins in neurally derived blood exosomes: A case-control study. Alzheimers Dement 11:600-607 e601. 10.1016/j.jalz.2014.06.008

Fowler CD. 2019. NeuroEVs: characterizing extracellular vesicles generated in the neural domain. Journal of Neuroscience 39:9262-9268. 10.1523/JNEUROSCI.0146-18.2019

Fromer M, Pocklington AJ, Kavanagh DH, Williams HJ, Dwyer S, Gormley P, Georgieva L, Rees E, Palta P, Ruderfer DM, Carrera N, Humphreys I, Johnson JS, Roussos P, Barker DD, Banks E, Milanova V, Grant SG, Hannon E, Rose SA, Chambert K, Mahajan M, Scolnick EM, Moran JL, Kirov G, Palotie A, McCarroll SA, Holmans P, Sklar P, Owen MJ, Purcell SM, and O'Donovan MC. 2014. De novo mutations in schizophrenia implicate synaptic networks. Nature 506:179-184. 10.1038/nature12929

Fruhbeis C, Frohlich D, Kuo WP, Amphornrat J, Thilemann S, Saab AS, Kirchhoff F, Mobius W, Goebbels S, Nave KA, Schneider A, Simons M, Klugmann M, Trotter J, and Kramer-Albers EM. 2013. Neurotransmitter-triggered transfer of exosomes mediates oligodendrocyte-neuron communication. PLoS Biology 11:e1001604. 10.1371/journal.pbio.1001604

Galbo PM, Jr., Ciesielski MJ, Figel S, Maguire O, Qiu J, Wiltsie L, Minderman H, and Fenstermaker RA. 2017. Circulating CD9+/GFAP+/survivin+ exosomes in malignant glioma patients following survivin vaccination. Oncotarget 8:114722-114735. 10.18632/oncotarget.21773

Goetzl EJ, Boxer A, Schwartz JB, Abner EL, Petersen RC, Miller BL, Carlson OD, Mustapic M, and Kapogiannis D. 2015. Low neural exosomal levels of cellular survival factors in Alzheimer's disease. Ann Clin Transl Neurol 2:769-773. 10.1002/acn3.211

Goetzl EJ, Kapogiannis D, Schwartz JB, Lobach IV, Goetzl L, Abner EL, Jicha GA, Karydas AM, Boxer A, and Miller BL. 2016a. Decreased synaptic proteins in neuronal exosomes of frontotemporal dementia and Alzheimer's disease. FASEB Journal 30:4141-4148. 10.1096/fj.201600816R

GoetzI EJ, Mustapic M, Kapogiannis D, Eitan E, Lobach IV, Goetzl L, Schwartz JB, and Miller BL. 2016 b. Cargo proteins of plasma astrocyte-derived exosomes in Alzheimer's disease. FASEB Journal 30:3853-3859. 10.1096/fj.201600756R

PeerJ reviewing PDF | (2020:04:47467:1:1:NEW 7 Jul 2020) 
667

668

669

670

671

672

673

674

675

676

677

678

679

680

681

682

683

684

685

686

687

688

689

690

691

692

693

694

695

696

697

698

699

700

701

702

703

704

705

706

707

708

709

710

711

712

713

714

Goldie BJ, Dun MD, Lin M, Smith ND, Verrills NM, Dayas CV, and Cairns MJ. 2014. Activity-associated miRNA are packaged in Map1b-enriched exosomes released from depolarized neurons. Nucleic Acids Research 42:9195-9208. 10.1093/nar/gku594

Guloksuz S, and van Os J. 2018. The slow death of the concept of schizophrenia and the painful birth of the psychosis spectrum. Psychological Medicine 48:229-244. 10.1017/S0033291717001775

Guy W. 1976. Clinical Global Impression. In: Department of Health E, and Welfare, editor. ECDEU Assessment Manual for Psychopharmacology.

Hall J, Trent S, Thomas KL, O'Donovan MC, and Owen MJ. 2015. Genetic risk for schizophrenia: convergence on synaptic pathways involved in plasticity. Biological Psychiatry 77:52-58. 10.1016/j.biopsych.2014.07.011

Han KS, Cooke SF, and Xu W. 2017. Experience-dependent equilibration of AMPAR-mediated synaptic transmission during the critical period. Cell Rep 18:892-904. 10.1016/j.celrep.2016.12.084

Hanley JG. 2018. The regulation of AMPA receptor endocytosis by dynamic protein-protein interactions. Frontiers in Cellular Neuroscience 12:362. 10.3389/fncel.2018.00362

Haslene-Hox H, Oveland E, Berg KC, Kolmannskog O, Woie K, Salvesen HB, Tenstad O, and Wiig H. 2011. A new method for isolation of interstitial fluid from human solid tumors applied to proteomic analysis of ovarian carcinoma tissue. PloS One 6:e19217. 10.1371/journal.pone.0019217

Hayashi-Takagi A, Takaki M, Graziane N, Seshadri S, Murdoch H, Dunlop AJ, Makino Y, Seshadri AJ, Ishizuka K, Srivastava DP, Xie Z, Baraban JM, Houslay MD, Tomoda T, Brandon NJ, Kamiya A, Yan Z, Penzes P, and Sawa A. 2010. Disrupted-in-Schizophrenia 1 (DISC1) regulates spines of the glutamate synapse via Rac1. Nature Neuroscience 13:327-332. 10.1038/nn.2487

Hulsen T, de Vlieg J, and Alkema W. 2008. BioVenn - a web application for the comparison and visualization of biological lists using area-proportional Venn diagrams. BMC Genomics 9:488. 10.1186/1471-2164-9-488

Hunt GE, Large MM, Cleary M, Lai HMX, and Saunders JB. 2018. Prevalence of comorbid substance use in schizophrenia spectrum disorders in community and clinical settings, 1990-2017: Systematic review and meta-analysis. Drug and Alcohol Dependence 191:234-258. 10.1016/j.drugalcdep.2018.07.011

Jakobsen AS, Speyer H, Norgaard HCB, Karlsen M, Hjorthoj C, Krogh J, Mors O, Nordentoft M, and Toft U. 2018. Dietary patterns and physical activity in people with schizophrenia and increased waist circumference. Schizophrenia Research 199:109-115. 10.1016/j.schres.2018.03.016

Jamaly S, Ramberg C, Olsen R, Latysheva N, Webster P, Sovershaev T, Braekkan SK, and Hansen JB. 2018. Impact of preanalytical conditions on plasma concentration and size distribution of extracellular vesicles using Nanoparticle Tracking Analysis. Scientific Reports 8:17216. 10.1038/s41598-01835401-8

Kalra H, Simpson RJ, Ji H, Aikawa E, Altevogt P, Askenase P, Bond VC, Borras FE, Breakefield X, Budnik V, Buzas E, Camussi G, Clayton A, Cocucci E, Falcon-Perez JM, Gabrielsson S, Gho YS, Gupta D, Harsha HC, Hendrix A, Hill AF, Inal JM, Jenster G, Kramer-Albers EM, Lim SK, Llorente A, Lotvall J, Marcilla A, Mincheva-Nilsson L, Nazarenko I, Nieuwland R, Nolte-'t Hoen EN, Pandey A, Patel T, Piper MG, Pluchino S, Prasad TS, Rajendran L, Raposo G, Record M, Reid GE, Sanchez-Madrid F, Schiffelers RM, Siljander P, Stensballe A, Stoorvogel W, Taylor D, Thery C, Valadi $H$, van Balkom BW, Vazquez J, Vidal M, Wauben MH, Yanez-Mo M, Zoeller M, and Mathivanan S. 2012. Vesiclepedia: a compendium for extracellular vesicles with continuous community annotation. PLoS Biology 10:e1001450. 10.1371/journal.pbio.1001450

Kapogiannis D, Boxer A, Schwartz JB, Abner EL, Biragyn A, Masharani U, Frassetto L, Petersen RC, Miller $B L$, and Goetzl EJ. 2015. Dysfunctionally phosphorylated type 1 insulin receptor substrate in neural-derived blood exosomes of preclinical Alzheimer's disease. FASEB Journal 29:589-596. 10.1096/fj.14-262048

PeerJ reviewing PDF | (2020:04:47467:1:1:NEW 7 Jul 2020) 
715

716

717

718

719

720

721

722

723

724

725

726

727

728

729

730

731

732

733

734

735

736

737

738

739

740

741

742

743

744

745

746

747

748

749

750

751

752

753

754

755

756

757

758

759

760

761

762

Kapogiannis D, Dobrowolny H, Tran J, Mustapic M, Frodl T, Meyer-Lotz G, Schiltz K, Schanze D, Rietschel M, Bernstein HG, and Steiner J. 2019a. Insulin-signaling abnormalities in drug-naive first-episode schizophrenia: Transduction protein analyses in extracellular vesicles of putative neuronal origin. European Psychiatry 62:124-129. 10.1016/j.eurpsy.2019.08.012

Kapogiannis D, Mustapic M, Shardell MD, Berkowitz ST, Diehl TC, Spangler RD, Tran J, Lazaropoulos MP, Chawla S, Gulyani S, Eitan E, An Y, Huang CW, Oh ES, Lyketsos CG, Resnick SM, Goetzl EJ, and Ferrucci L. 2019b. Association of extracellular vesicle biomarkers with Alzheimer disease in the Baltimore longitudinal study of aging. JAMA Neurol. 10.1001/jamaneurol.2019.2462

Karageorgiou V, Milas GP, and Michopoulos I. 2019. Neutrophil-to-lymphocyte ratio in schizophrenia: A systematic review and meta-analysis. Schizophrenia Research 206:4-12. 10.1016/j.schres.2018.12.017

Karasu E, Eisenhardt SU, Harant J, and Huber-Lang M. 2018. Extracellular vesicles: Packages sent with complement. Frontiers in Immunology 9:721. 10.3389/fimmu.2018.00721

Karimi N, Cvjetkovic A, Jang SC, Crescitelli R, Hosseinpour Feizi MA, Nieuwland R, Lotvall J, and Lasser C. 2018. Detailed analysis of the plasma extracellular vesicle proteome after separation from lipoproteins. Cellular and Molecular Life Sciences 75:2873-2886. 10.1007/s00018-018-2773-4

Keshavan MS, Giedd J, Lau JY, Lewis DA, and Paus T. 2014. Changes in the adolescent brain and the pathophysiology of psychotic disorders. Lancet Psychiatry 1:549-558. 10.1016/S22150366(14)00081-9

Kirov G, Pocklington AJ, Holmans P, Ivanov D, Ikeda M, Ruderfer D, Moran J, Chambert K, Toncheva D, Georgieva L, Grozeva D, Fjodorova M, Wollerton R, Rees E, Nikolov I, van de Lagemaat LN, Bayes A, Fernandez E, Olason PI, Bottcher Y, Komiyama NH, Collins MO, Choudhary J, Stefansson K, Stefansson H, Grant SG, Purcell S, Sklar P, O'Donovan MC, and Owen MJ. 2012. De novo CNV analysis implicates specific abnormalities of postsynaptic signalling complexes in the pathogenesis of schizophrenia. Molecular Psychiatry 17:142-153. 10.1038/mp.2011.154

Kroken RA, Sommer IE, Steen VM, Dieset I, and Johnsen E. 2018. Constructing the immune signature of schizophrenia for clinical use and research; An integrative review translating descriptives into diagnostics. Front Psychiatry 9:753. 10.3389/fpsyt.2018.00753

Louveau A, Smirnov I, Keyes TJ, Eccles JD, Rouhani SJ, Peske JD, Derecki NC, Castle D, Mandell JW, Lee KS, Harris TH, and Kipnis J. 2015. Structural and functional features of central nervous system lymphatic vessels. Nature 523:337-341. 10.1038/nature14432

Matsumoto J, Stewart T, Sheng L, Li N, Bullock K, Song N, Shi M, Banks WA, and Zhang J. 2017. Transmission of alpha-synuclein-containing erythrocyte-derived extracellular vesicles across the blood-brain barrier via adsorptive mediated transcytosis: another mechanism for initiation and progression of Parkinson's disease? Acta Neuropathol Commun 5:71. 10.1186/s40478-017-04704

Mauri MC, Di Pace C, Reggiori A, Paletta S, and Colasanti A. 2017. Primary psychosis with comorbid drug abuse and drug-induced psychosis: Diagnostic and clinical evolution at follow up. Asian Journal of Psychiatry 29:117-122. 10.1016/j.ajp.2017.04.014

Mazza MG, Lucchi S, Rossetti A, and Clerici M. 2019. Neutrophil-lymphocyte ratio, monocytelymphocyte ratio and platelet-lymphocyte ratio in non-affective psychosis: A meta-analysis and systematic review. World Journal of Biological Psychiatry:1-13.

10.1080/15622975.2019.1583371

Mi H, Muruganujan A, and Thomas PD. 2013. PANTHER in 2013: modeling the evolution of gene function, and other gene attributes, in the context of phylogenetic trees. Nucleic Acids Research 41:D377-386. 10.1093/nar/gks1118

Mobarrez F, Nybom R, Johansson V, Hultman CM, Wallen H, Landen M, and Wetterberg L. 2013. Microparticles and microscopic structures in three fractions of fresh cerebrospinal fluid in

PeerJ reviewing PDF | (2020:04:47467:1:1:NEW 7 Jul 2020) 
802

803

804

805

806

807

808

809

810

schizophrenia: case report of twins. Schizophrenia Research 143:192-197.

10.1016/j.schres.2012.10.030

Mullier F, Bailly N, Chatelain C, Chatelain B, and Dogne JM. 2013. Pre-analytical issues in the measurement of circulating microparticles: current recommendations and pending questions. Journal of Thrombosis and Haemostasis 11:693-696. 10.1111/jth.12171

Mustapic M, Eitan E, Werner JK, Jr., Berkowitz ST, Lazaropoulos MP, Tran J, Goetzl EJ, and Kapogiannis D. 2017. Plasma extracellular vesicles enriched for neuronal origin: a potential window into brain pathologic processes. Frontiers in Neuroscience 11:278. 10.3389/fnins.2017.00278

Pardinas AF, Holmans P, Pocklington AJ, Escott-Price V, Ripke S, Carrera N, Legge SE, Bishop S, Cameron D, Hamshere ML, Han J, Hubbard L, Lynham A, Mantripragada K, Rees E, MacCabe JH, McCarroll SA, Baune BT, Breen G, Byrne EM, Dannlowski U, Eley TC, Hayward C, Martin NG, McIntosh AM, Plomin R, Porteous DJ, Wray NR, Caballero A, Geschwind DH, Huckins LM, Ruderfer DM, Santiago E, Sklar P, Stahl EA, Won H, Agerbo E, Als TD, Andreassen OA, Baekvad-Hansen M, Mortensen $\mathrm{PB}$, Pedersen $\mathrm{CB}$, Borglum AD, Bybjerg-Grauholm J, Djurovic S, Durmishi N, Pedersen MG, Golimbet V, Grove J, Hougaard DM, Mattheisen M, Molden E, Mors O, Nordentoft M, Pejovic-Milovancevic M, Sigurdsson E, Silagadze T, Hansen CS, Stefansson K, Stefansson H, Steinberg S, Tosato S, Werge T, Consortium G, Consortium C, Collier DA, Rujescu D, Kirov G, Owen MJ, O'Donovan MC, and Walters JTR. 2018. Common schizophrenia alleles are enriched in mutation-intolerant genes and in regions under strong background selection. Nature Genetics 50:381-389. 10.1038/s41588-018-0059-2

Pastuzyn ED, Day CE, Kearns RB, Kyrke-Smith M, Taibi AV, McCormick J, Yoder N, Belnap DM, Erlendsson S, Morado DR, Briggs JAG, Feschotte C, and Shepherd JD. 2018. The neuronal gene Arc encodes a repurposed retrotransposon Gag protein that mediates intercellular RNA transfer. Cell 172:275-288 e218. 10.1016/j.cell.2017.12.024

Penzes P, and Remmers C. 2012. Kalirin signaling: implications for synaptic pathology. Molecular Neurobiology 45:109-118. 10.1007/s12035-011-8223-z

Pillinger T, D'Ambrosio E, McCutcheon R, and O DH. 2018. Is psychosis a multisystem disorder? A metareview of central nervous system, immune, cardiometabolic, and endocrine alterations in firstepisode psychosis and perspective on potential models. Molecular Psychiatry. 10.1038/s41380018-0058-9

Pocklington AJ, Rees E, Walters JT, Han J, Kavanagh DH, Chambert KD, Holmans P, Moran JL, McCarroll SA, Kirov G, O'Donovan MC, and Owen MJ. 2015. Novel findings from CNVs implicate inhibitory and excitatory signaling complexes in schizophrenia. Neuron 86:1203-1214. 10.1016/j.neuron.2015.04.022

Pries LK, Guloksuz S, Ten Have M, de Graaf R, van Dorsselaer S, Gunther N, Rauschenberg C, Reininghaus U, Radhakrishnan R, Bak M, Rutten BPF, and van Os J. 2018. Evidence that environmental and familial risks for psychosis additively impact a multidimensional subthreshold psychosis syndrome. Schizophrenia Bulletin 44:710-719. 10.1093/schbul/sby051

Ranson A, Broom E, Powell A, Chen F, Major G, and Hall J. 2019. Top-down suppression of sensory cortex in an NMDAR hypofunction model of psychosis. Schizophrenia Bulletin 45:1349-1357. $10.1093 /$ schbul/sby190

Raposo G, and Stoorvogel W. 2013. Extracellular vesicles: exosomes, microvesicles, and friends. Journal of Cell Biology 200:373-383. 10.1083/jcb.201211138

Sachs NA, Sawa A, Holmes SE, Ross CA, DeLisi LE, and Margolis RL. 2005. A frameshift mutation in Disrupted in Schizophrenia 1 in an American family with schizophrenia and schizoaffective disorder. Molecular Psychiatry 10:758-764. 10.1038/sj.mp.4001667

Schizophrenia Working Group of the Psychiatric Genomics C. 2014. Biological insights from 108 schizophrenia-associated genetic loci. Nature 511:421-427. 10.1038/nature13595 
811

812

813

814

815

816

817

818

819

820

821

822

823

824

825

826

827

828

829

830

831

832

833

834

835

836

837

838

839

840

841

842

843

844

845

846

847

848

849

850

851

852

853

854

855

856

857

858

Slomka A, Urban SK, Lukacs-Kornek V, Zekanowska E, and Kornek M. 2018. Large extracellular vesicles: Have we found the holy grail of inflammation? Frontiers in Immunology 9:2723.

10.3389/fimmu.2018.02723

Smith PH, Mazure CM, and McKee SA. 2014. Smoking and mental illness in the U.S. population. Tobacco Control 23:e147-153. 10.1136/tobaccocontrol-2013-051466

Soler J, Fananas L, Parellada M, Krebs MO, Rouleau GA, and Fatjo-Vilas M. 2018. Genetic variability in scaffolding proteins and risk for schizophrenia and autism-spectrum disorders: a systematic review. Journal of Psychiatry and Neuroscience 43:223-244.

The Human protein Atlas. n.d. The brain-specific proteome. Available at http://www.proteinatlas.org/humanproteome/tissue/brain (accessed November, 22, 2018 2018).

Thery C, Witwer KW, Aikawa E, Alcaraz MJ, Anderson JD, Andriantsitohaina R, Antoniou A, Arab T, Archer F, Atkin-Smith GK, Ayre DC, Bach JM, Bachurski D, Baharvand H, Balaj L, Baldacchino S, Bauer NN, Baxter AA, Bebawy M, Beckham C, Bedina Zavec A, Benmoussa A, Berardi AC, Bergese $P$, Bielska E, Blenkiron C, Bobis-Wozowicz S, Boilard E, Boireau W, Bongiovanni A, Borras FE, Bosch S, Boulanger CM, Breakefield X, Breglio AM, Brennan MA, Brigstock DR, Brisson A, Broekman ML, Bromberg JF, Bryl-Gorecka P, Buch S, Buck AH, Burger D, Busatto S, Buschmann D, Bussolati B, Buzas El, Byrd JB, Camussi G, Carter DR, Caruso S, Chamley LW, Chang YT, Chen C, Chen S, Cheng L, Chin AR, Clayton A, Clerici SP, Cocks A, Cocucci E, Coffey RJ, Cordeiro-da-Silva A, Couch Y, Coumans FA, Coyle B, Crescitelli R, Criado MF, D'Souza-Schorey C, Das S, Datta Chaudhuri A, de Candia P, De Santana EF, De Wever O, Del Portillo HA, Demaret T, Deville S, Devitt A, Dhondt B, Di Vizio D, Dieterich LC, Dolo V, Dominguez Rubio AP, Dominici M, Dourado MR, Driedonks TA, Duarte FV, Duncan HM, Eichenberger RM, Ekstrom K, El Andaloussi S, ElieCaille C, Erdbrugger U, Falcon-Perez JM, Fatima F, Fish JE, Flores-Bellver M, Forsonits A, FreletBarrand A, Fricke F, Fuhrmann G, Gabrielsson S, Gamez-Valero A, Gardiner C, Gartner K, Gaudin R, Gho YS, Giebel B, Gilbert C, Gimona M, Giusti I, Goberdhan DC, Gorgens A, Gorski SM, Greening DW, Gross JC, Gualerzi A, Gupta GN, Gustafson D, Handberg A, Haraszti RA, Harrison P, Hegyesi $H$, Hendrix A, Hill AF, Hochberg FH, Hoffmann KF, Holder B, Holthofer $H$, Hosseinkhani B, Hu G, Huang Y, Huber V, Hunt S, Ibrahim AG, Ikezu T, Inal JM, Isin M, Ivanova A, Jackson HK, Jacobsen $S$, Jay SM, Jayachandran $M$, Jenster $G$, Jiang $L$, Johnson SM, Jones JC, Jong A, JovanovicTalisman T, Jung S, Kalluri R, Kano SI, Kaur S, Kawamura Y, Keller ET, Khamari D, Khomyakova E, Khvorova A, Kierulf P, Kim KP, Kislinger T, Klingeborn M, Klinke DJ, 2nd, Kornek M, Kosanovic MM, Kovacs AF, Kramer-Albers EM, Krasemann S, Krause M, Kurochkin IV, Kusuma GD, Kuypers S, Laitinen S, Langevin SM, Languino LR, Lannigan J, Lasser C, Laurent LC, Lavieu G, Lazaro-Ibanez E, Le Lay S, Lee MS, Lee YXF, Lemos DS, Lenassi M, Leszczynska A, Li IT, Liao K, Libregts SF, Ligeti E, Lim R, Lim SK, Line A, Linnemannstons K, Llorente A, Lombard CA, Lorenowicz MJ, Lorincz AM, Lotvall J, Lovett J, Lowry MC, Loyer X, Lu Q, Lukomska B, Lunavat TR, Maas SL, Malhi H, Marcilla A, Mariani J, Mariscal J, Martens-Uzunova ES, Martin-Jaular L, Martinez MC, Martins VR, Mathieu M, Mathivanan S, Maugeri M, McGinnis LK, McVey MJ, Meckes DG, Jr., Meehan KL, Mertens I, Minciacchi VR, Moller A, Moller Jorgensen M, Morales-Kastresana A, Morhayim J, Mullier F, Muraca M, Musante L, Mussack V, Muth DC, Myburgh KH, Najrana T, Nawaz M, Nazarenko I, Nejsum P, Neri C, Neri T, Nieuwland R, Nimrichter L, Nolan JP, Nolte-'t Hoen EN, Noren Hooten N, O'Driscoll L, O'Grady T, O'Loghlen A, Ochiya T, Olivier M, Ortiz A, Ortiz LA, Osteikoetxea X, Ostergaard O, Ostrowski M, Park J, Pegtel DM, Peinado H, Perut F, Pfaffl MW, Phinney DG, Pieters BC, Pink RC, Pisetsky DS, Pogge von Strandmann E, Polakovicova I, Poon IK, Powell BH, Prada I, Pulliam L, Quesenberry P, Radeghieri A, Raffai RL, Raimondo S, Rak J, Ramirez MI, Raposo G, Rayyan MS, Regev-Rudzki N, Ricklefs FL, Robbins PD, Roberts DD, Rodrigues SC, Rohde E, Rome S, Rouschop KM, Rughetti A, Russell AE, Saa P, Sahoo S, Salas-Huenuleo E,

PeerJ reviewing PDF | (2020:04:47467:1:1:NEW 7 Jul 2020) 
859

860

861

862

863

864

865

866

867

868

869

870

871

872

873

874

875

876

877

878

879

880

881

882

883

884

885

886

887

888

889

890

891

892

893

894

895

896

897

898

899

900

901

902

903

904

905

906

Sanchez C, Saugstad JA, Saul MJ, Schiffelers RM, Schneider R, Schoyen TH, Scott A, Shahaj E, Sharma S, Shatnyeva O, Shekari F, Shelke GV, Shetty AK, Shiba K, Siljander PR, Silva AM, Skowronek A, Snyder OL, 2nd, Soares RP, Sodar BW, Soekmadji C, Sotillo J, Stahl PD, Stoorvogel W, Stott SL, Strasser EF, Swift S, Tahara H, Tewari M, Timms K, Tiwari S, Tixeira R, Tkach M, Toh WS, Tomasini R, Torrecilhas AC, Tosar JP, Toxavidis V, Urbanelli L, Vader P, van Balkom BW, van der Grein SG, Van Deun J, van Herwijnen MJ, Van Keuren-Jensen K, van Niel G, van Royen ME, van Wijnen AJ, Vasconcelos MH, Vechetti IJ, Jr., Veit TD, Vella LJ, Velot E, Verweij FJ, Vestad B, Vinas JL, Visnovitz T, Vukman KV, Wahlgren J, Watson DC, Wauben MH, Weaver A, Webber JP, Weber V, Wehman AM, Weiss DJ, Welsh JA, Wendt S, Wheelock AM, Wiener Z, Witte L, Wolfram J, Xagorari A, Xander P, Xu J, Yan X, Yanez-Mo M, Yin H, Yuana Y, Zappulli V, Zarubova J, Zekas V, Zhang JY, Zhao Z, Zheng L, Zheutlin AR, Zickler AM, Zimmermann P, Zivkovic AM, Zocco D, and Zuba-Surma EK. 2018. Minimal information for studies of extracellular vesicles 2018 (MISEV2018): a position statement of the International Society for Extracellular Vesicles and update of the MISEV2014 guidelines. J Extracell Vesicles 7:1535750. 10.1080/20013078.2018.1535750

Thiebes S, Leicht G, Curic S, Steinmann S, Polomac N, Andreou C, Eichler I, Eichler L, Zollner C, Gallinat J, Hanganu-Opatz I, and Mulert C. 2017. Glutamatergic deficit and schizophrenia-like negative symptoms: new evidence from ketamine-induced mismatch negativity alterations in healthy male humans. Journal of Psychiatry and Neuroscience 42:273-283. 10.1503/jpn.160187

Thomson PA, Duff B, Blackwood DH, Romaniuk L, Watson A, Whalley HC, Li X, Dauvermann MR, Moorhead TW, Bois C, Ryan NM, Redpath H, Hall L, Morris SW, van Beek EJ, Roberts N, Porteous DJ, St Clair D, Whitcher B, Dunlop J, Brandon NJ, Hughes ZA, Hall J, McIntosh A, and Lawrie SM. 2016. Balanced translocation linked to psychiatric disorder, glutamate, and cortical structure/function. NPJ Schizophr 2:16024. 10.1038/npjschz.2016.24

Tropea D, Hardingham N, Millar K, and Fox K. 2018. Mechanisms underlying the role of DISC1 in synaptic plasticity. Journal of Physiology 596:2747-2771. 10.1113/JP274330

Tyanova S, Temu T, Sinitcyn P, Carlson A, Hein MY, Geiger T, Mann M, and Cox J. 2016. The Perseus computational platform for comprehensive analysis of (prote)omics data. Nat Methods 13:731740. 10.1038/nmeth.3901

Uhlen M, Fagerberg L, Hallstrom BM, Lindskog C, Oksvold P, Mardinoglu A, Sivertsson A, Kampf C, Sjostedt E, Asplund A, Olsson I, Edlund K, Lundberg E, Navani S, Szigyarto CA, Odeberg J, Djureinovic D, Takanen JO, Hober S, Alm T, Edqvist PH, Berling H, Tegel H, Mulder J, Rockberg J, Nilsson P, Schwenk JM, Hamsten M, von Feilitzen K, Forsberg M, Persson L, Johansson F, Zwahlen M, von Heijne G, Nielsen J, and Ponten F. 2015. Proteomics. Tissue-based map of the human proteome. Science 347:1260419. 10.1126/science.1260419

van Niel G, D'Angelo G, and Raposo G. 2018. Shedding light on the cell biology of extracellular vesicles. Nature Reviews: Molecular Cell Biology 19:213-228. 10.1038/nrm.2017.125

Vaudel M, Breiter D, Beck F, Rahnenfuhrer J, Martens L, and Zahedi RP. 2013. D-score: a search engine independent MD-score. Proteomics 13:1036-1041. 10.1002/pmic.201200408

Vaudel M, Burkhart JM, Zahedi RP, Oveland E, Berven FS, Sickmann A, Martens L, and Barsnes H. 2015. PeptideShaker enables reanalysis of MS-derived proteomics data sets. Nature Biotechnology 33:22-24. 10.1038/nbt.3109

Vizcaino JA, Csordas A, del-Toro N, Dianes JA, Griss J, Lavidas I, Mayer G, Perez-Riverol Y, Reisinger F, Ternent T, Xu QW, Wang R, and Hermjakob H. 2016. 2016 update of the PRIDE database and its related tools. Nucleic Acids Research 44:D447-456. 10.1093/nar/gkv1145

Vizcaino JA, Deutsch EW, Wang R, Csordas A, Reisinger F, Rios D, Dianes JA, Sun Z, Farrah T, Bandeira N, Binz PA, Xenarios I, Eisenacher M, Mayer G, Gatto L, Campos A, Chalkley RJ, Kraus HJ, Albar JP, Martinez-Bartolome S, Apweiler R, Omenn GS, Martens L, Jones AR, and Hermjakob H. 2014.

PeerJ reviewing PDF | (2020:04:47467:1:1:NEW 7 Jul 2020) 
907

908

909

910

911

912

913

914

915

916

917

918

919

920

921

922

923

924

925

926

927

928

929

930

931

932

933

934

935
ProteomeXchange provides globally coordinated proteomics data submission and dissemination. Nature Biotechnology 32:223-226. 10.1038/nbt.2839

Wearne TA, and Cornish JL. 2018. A Comparison of methamphetamine-induced psychosis and schizophrenia: A review of positive, negative, and cognitive symptomatology. Front Psychiatry 9:491. 10.3389/fpsyt.2018.00491

Wijtenburg SA, Kapogiannis D, Korenic SA, Mullins RJ, Tran J, Gaston FE, Chen S, Mustapic M, Hong LE, and Rowland LM. 2019. Brain insulin resistance and altered brain glucose are related to memory impairments in schizophrenia. Schizophrenia Research 208:324-330. 10.1016/j.schres.2019.01.031

Wilson L, Szigeti A, Kearney A, and Clarke M. 2018. Clinical characteristics of primary psychotic disorders with concurrent substance abuse and substance-induced psychotic disorders: A systematic review. Schizophrenia Research 197:78-86. 10.1016/j.schres.2017.11.001

Woo JJ, Pouget JG, Zai CC, and Kennedy JL. 2019. The complement system in schizophrenia: where are we now and what's next? Molecular Psychiatry. 10.1038/s41380-019-0479-0

Yanez-Mo M, Siljander PR, Andreu Z, Zavec AB, Borras FE, Buzas El, Buzas K, Casal E, Cappello F, Carvalho J, Colas E, Cordeiro-da Silva A, Fais S, Falcon-Perez JM, Ghobrial IM, Giebel B, Gimona M, Graner M, Gursel I, Gursel M, Heegaard NH, Hendrix A, Kierulf P, Kokubun K, Kosanovic M, Kralj-Iglic V, Kramer-Albers EM, Laitinen S, Lasser C, Lener T, Ligeti E, Line A, Lipps G, Llorente A, Lotvall J, Mancek-Keber M, Marcilla A, Mittelbrunn M, Nazarenko I, Nolte-'t Hoen EN, Nyman TA, O'Driscoll L, Olivan M, Oliveira C, Pallinger E, Del Portillo HA, Reventos J, Rigau M, Rohde E, Sammar M, Sanchez-Madrid F, Santarem N, Schallmoser K, Ostenfeld MS, Stoorvogel W, Stukelj $\mathrm{R}$, Van der Grein SG, Vasconcelos MH, Wauben MH, and De Wever O. 2015. Biological properties of extracellular vesicles and their physiological functions. J Extracell Vesicles 4:27066. 10.3402/jev.v4.27066

Zealberg JJ, and Brady KT. 1999. Substance abuse and emergency psychiatry. Psychiatric Clinics of North America 22:803-817. 10.1016/s0193-953x(05)70127-1

Zhong L, Cherry T, Bies CE, Florence MA, and Gerges NZ. 2009. Neurogranin enhances synaptic strength through its interaction with calmodulin. EMBO Journal 28:3027-3039. 10.1038/emboj.2009.236 


\section{Figure 1}

Concentration, size and protein content of EVs

Vesicle concentration (A), vesicle concentration versus size from nano-tracking analysis (B), vesicle diameter $(C)$ and protein concentration $(D)$ of isolated $E V$ fractions for psychotic patients during psychosis (T1) and in improved state (T2) and healthy controls (HC). P-values are given for significant differences. Bar shows mean value with standard deviation error bars. 
A
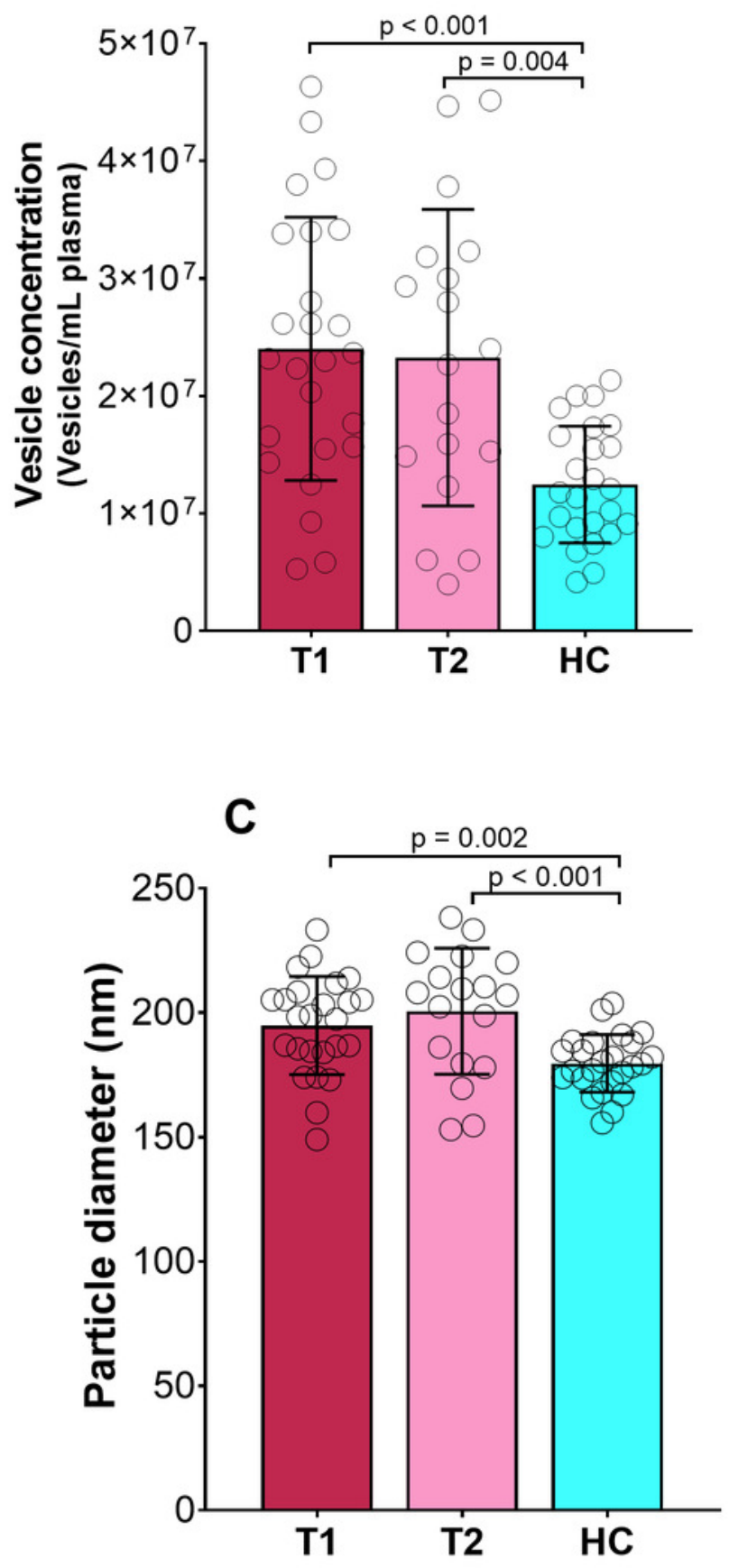

B

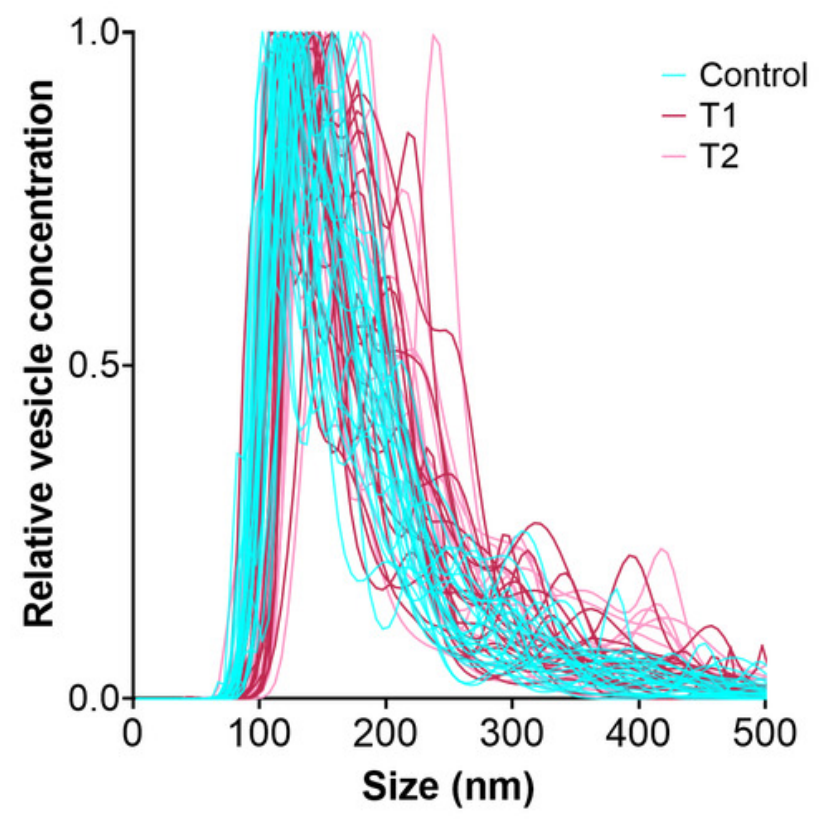

D

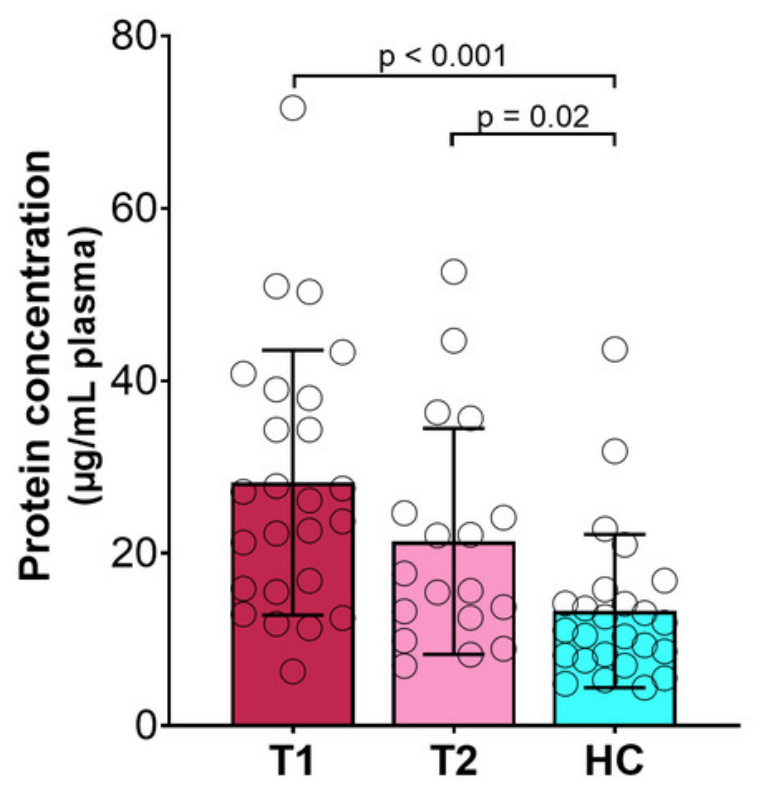




\section{Figure 2}

Overall proteomic findings

A) Venn diagram showing total number of identified proteins in psychotic patients during psychosis (T1) and in improved state (T2) and healthy controls (HC) and the overlap between sample groups. B) Volcano plot showing the p-value versus the fold change of all proteins for all three groups compared pairwise with each other (Student's t-test with multiple hypothesis correction, lines showing significance threshold (Significant at $p<0.05$, Artificial within groups variance $s 0=0.1)$ ).
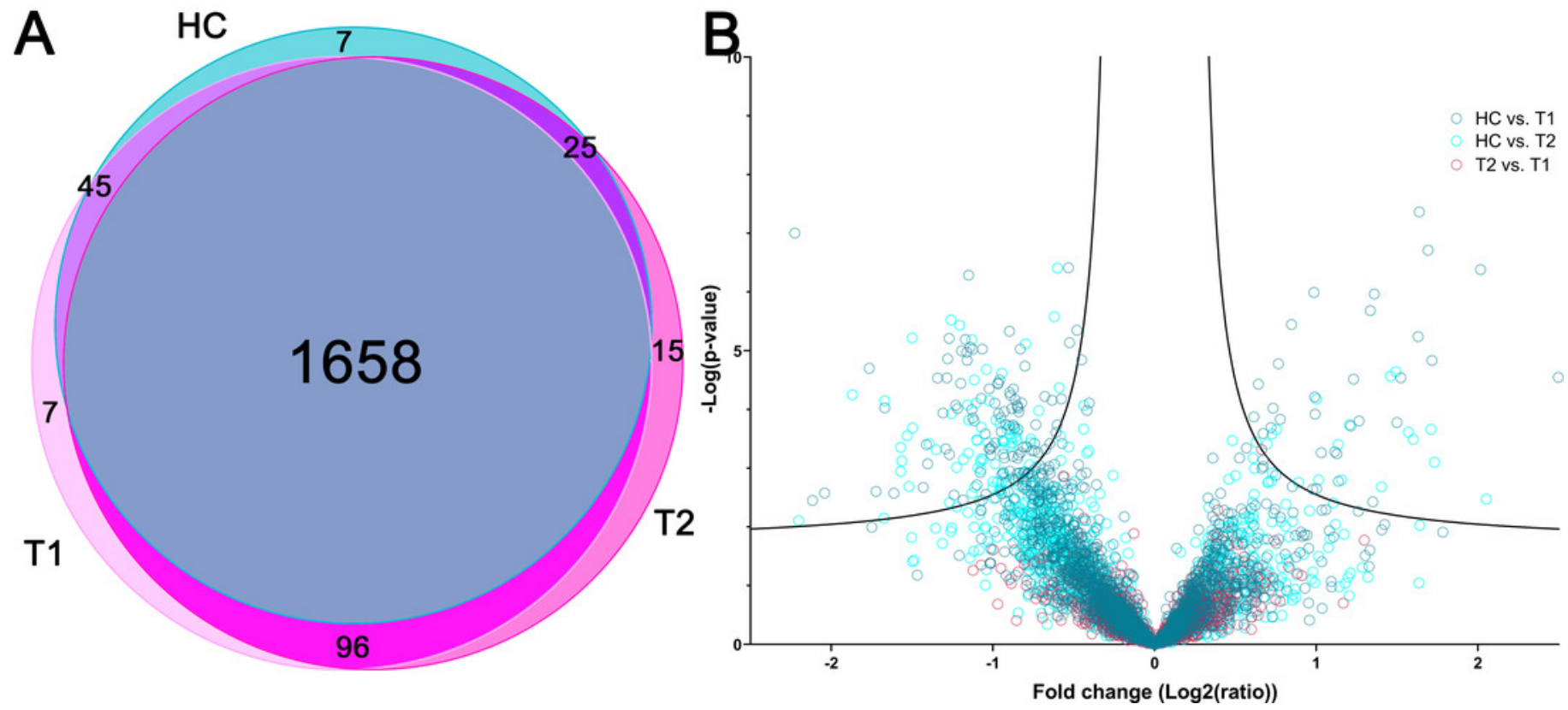
Figure 3

Total amount of brain-elevated proteins and significantly changed brain proteins

Scatter plot for normalized (divided by total sum within each sample) average precursor intensity with mean (bar) and standard deviation (error bars) for the five brain proteins identified as significantly different between psychotic patients during psychosis (T1) and/or in improved state (T2) and healthy controls (HC). A) Neurogranin (Q92686), B) Neuron-specific calcium-binding protein hippocalcin (HPCA, P84074), C) Kalirin (O60229), D) Beta-adducin (P35612), E) Ankyrin-2 (Q01484) and F) all 45 brain-elevated proteins

A. Neurogranin

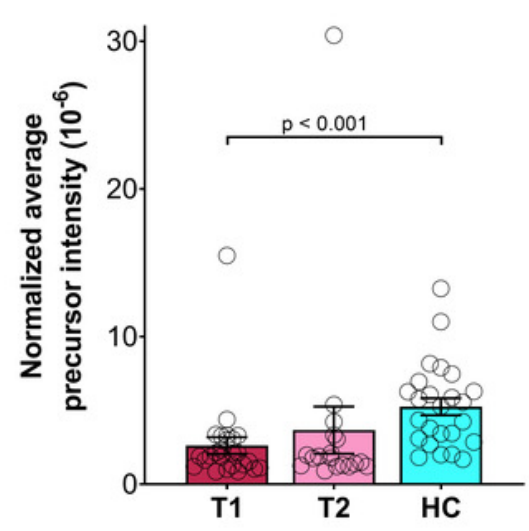

D. Beta-adducin

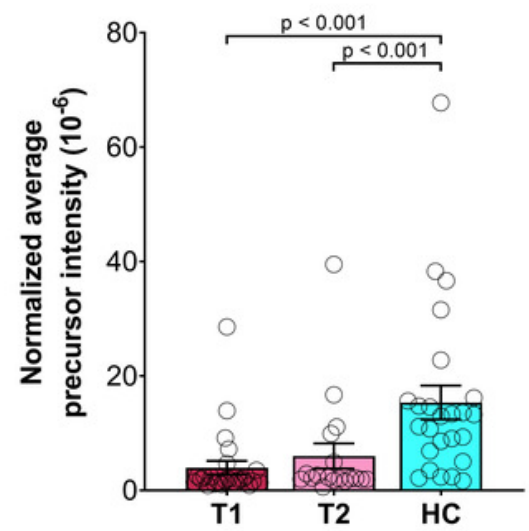

B. HPCA

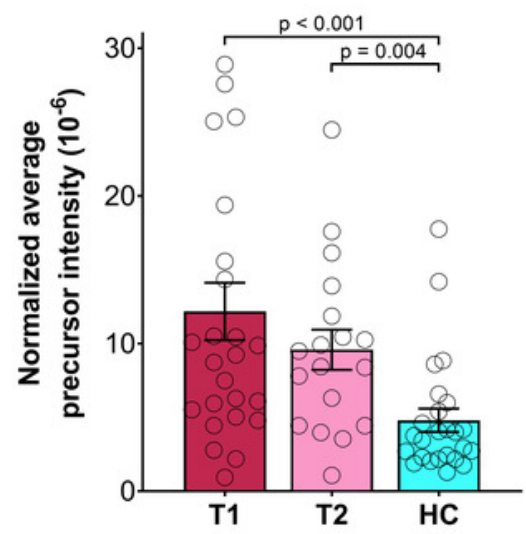

E. Ankyrin-2

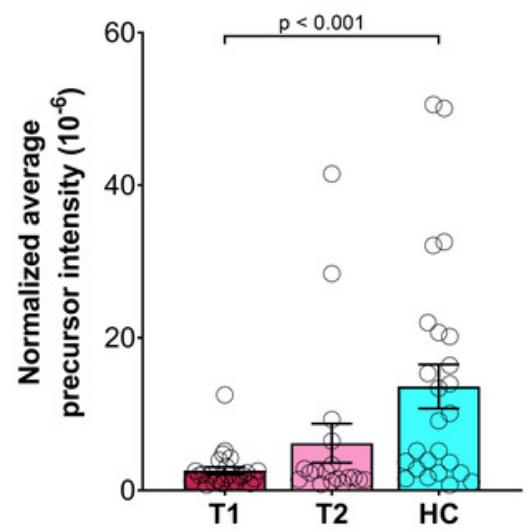

C. Kalirin

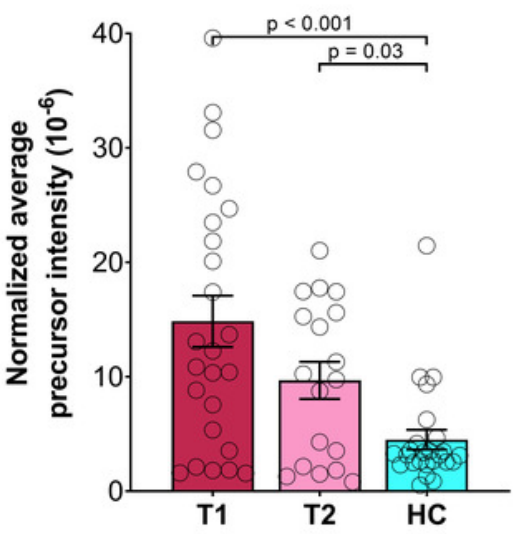

F. All brain proteins

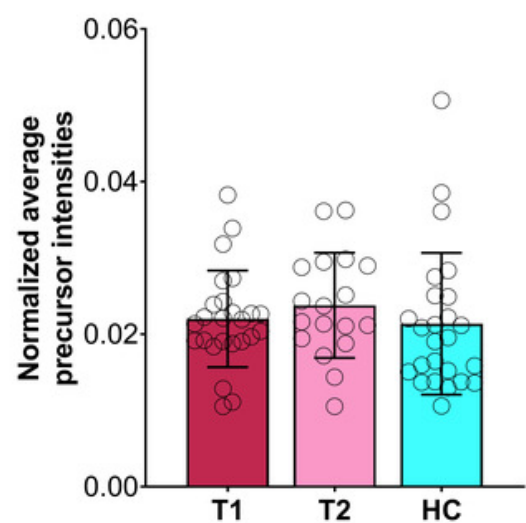




\section{Table $\mathbf{1}$ (on next page)}

Main characteristics of EVs
A) Main characteristics of EVs in patients at first sampling point (T1) and controls. Values given as mean (SD). B) Main characteristics in EVs from the 18 patients with complete data at both sampling time points (T1 and T2). Values given as mean (SD).C) Main characteristics of EVs according to time since debut of psychosis at T1. Values given as mean (SD). 


\begin{tabular}{|c|c|c|c|c|c|}
\hline Table 1A: T1 vs HC & \multicolumn{2}{|c|}{ Psychotic patients $(\mathrm{T} 1, \mathrm{n}=25)$} & \multicolumn{2}{|c|}{ Healthy Controls (HC, $\mathrm{n}=25$ ) } & $p$ - value ${ }^{1}$ \\
\hline Diameter of EVs $(\mathrm{nm})$ & \multicolumn{2}{|c|}{$195(20)$} & \multicolumn{2}{|c|}{$180(12)$} & $0.002^{2}$ \\
\hline Concentration of EVs (particles/ml plasma) & \multicolumn{2}{|c|}{$2.4 \times 10^{7}\left(1,1 \times 10^{7}\right)$} & \multicolumn{2}{|c|}{$1.2 \times 10^{7}\left(5.0 \times 10^{6}\right)$} & $<0.001^{2}$ \\
\hline Protein content EVs ( $\mu \mathrm{g} / \mathrm{ml}$ plasma) & \multicolumn{2}{|c|}{$28.2(15.4)$} & \multicolumn{2}{|c|}{$13.3(8.9)$} & $<0.001^{2}$ \\
\hline Table 1B: T1 vs T2 & Acute phase (T1) & Improved (T2) & Change & $95 \% \mathrm{Cl}$ & $p$-value ${ }^{3}$ \\
\hline CGI score, median & 7 & 4 & & & \\
\hline CGI score, mean & $6.5(0.65)$ & $3.8(1.23)$ & & & \\
\hline Diameter of EVs (nm) & $199(18)$ & $200(25)$ & 1 & $-17-13$ & 0.798 \\
\hline Concentration of EVs (particles/ml plasma) & $2.2 \times 10^{7}\left(1.0 \times 10^{7}\right)$ & $2.3 \times 10^{7}\left(1.3 \times 10^{7}\right)$ & $9.5 \times 10^{5}$ & $-8.6 \times 10^{6}-6.7 \times 10^{6}$ & 0.796 \\
\hline Protein concentration in EV fraction ( $\mu \mathrm{g} / \mathrm{ml}$ plasma) & $26.8(12.0)$ & $21.4(13.1)$ & -5.4 & $-5.1-15.9$ & 0.294 \\
\hline Table 1C: T1 & Psychotic patic & nts $(T 1, n=25)$ & Mean & $95 \% \mathrm{Cl}$ interval & p-value ${ }^{1}$ \\
\hline Years since debut of psychosis & $<1(n=10)$ & $\geq 1(n=15)$ & & & \\
\hline Months since debut of first psychosis & $4.1(4.8)$ & $102.4(83.7)$ & & & \\
\hline Concentration of EVs (particles/ml plasma) & $2.0 \times 10^{7}\left(8.3 \times 10^{6}\right)$ & $2.7 \times 10^{7}\left(1.2 \times 10^{7}\right)$ & $-7.4 \times 10^{6}$ & $-1.6 \times 10^{7}-1.7 \times 10^{6}$ & 0.106 \\
\hline Diameter of EVs (nm) & 193(14) & $196(23)$ & -3 & $-20-13$ & 0.678 \\
\hline Protein concentration in EV fraction $(\mu \mathrm{g} / \mathrm{ml}$ plasma) & $22.4(8.5)$ & $32.0(17.9)$ & 9.6 & $-22.2-3.0$ & 0.130 \\
\hline
\end{tabular}

${ }^{1}$ Two sample t-test. ${ }^{2}$ Equal variance not assumed. ${ }^{3}$ Paired $t$-test. 


\section{Table 2 (on next page)}

Significantly changed brain proteins

Overview of the five brain proteins identified as different between healthy controls (HC) and patients with psychosis (T1) and in improved state (T2). The table shows accession number in Uniprot, molecular weight (MW), number of validated peptides and spectra across all samples, and Average precursor intensity within each group given as mean \pm standard deviation (number of samples where the protein is identified). 


\begin{tabular}{|c|l|c|c|c|c|c|c|}
\hline \multirow{2}{*}{$\begin{array}{c}\text { Uniprot } \\
\text { Accession }\end{array}$} & Protein name & MW (kDa) & $\begin{array}{c}\text { \#Validated } \\
\text { Peptides }\end{array}$ & $\begin{array}{c}\text { \#Validated } \\
\text { Spectra }\end{array}$ & \multicolumn{3}{|c|}{ Average precursor intensity (Mean \pm SD (n)) } \\
\hline Q92686 & Neurogranin & 7,6 & 2 & 76 & $146020 \pm 80464(20)$ & $130421 \pm 153699(9)$ & $195775 \pm 403355(10)$ \\
\hline & $\begin{array}{l}\text { Neuron-specific calcium-binding protein } \\
\text { hippocalcin }\end{array}$ & 22,4 & 4 & 80 & $188914 \pm 114734(14)$ & $281593 \pm 145068(21)$ & $263648 \pm 145611(16)$ \\
\hline P84074 & 340,0 & 11 & 106 & $229014 \pm 142100(9)$ & $337939 \pm 176321(19)$ & $330904 \pm 115006(11)$ \\
\hline O60229 & Kalirin & 80,8 & 13 & 99 & $305652 \pm 169514(20)$ & $165875 \pm 63467(3)$ & $309466 \pm 201639(5)$ \\
\hline P35612 & Beta-adducin & 433,4 & 6 & 53 & $295801 \pm 111670(16)$ & $122702 \pm 9911(2)$ & $556426 \pm 745193(4)$ \\
\hline Q01484 & Ankyrin-2 & & & & &
\end{tabular}

